\title{
Cryogenic fracturing for reservoir stimulation - laboratory studies
}

\author{
Minsu Cha ${ }^{1}$, Xiaolong Yin ${ }^{1}$, Timothy Kneafsey ${ }^{2}$, Brent Johanson ${ }^{1}$, \\ Naif Alqahtani ${ }^{1}$, Jennifer Miskimins ${ }^{1}$, Taylor Patterson ${ }^{1}$, and $\mathrm{Yu}-\mathrm{Shu} \mathrm{Wu}^{1}$ \\ Prepared for Journal of Petroleum Science and Engineering \\ Special Issue: Hydraulic Fracture Stimulation in Unconventional Resources: \\ Status as of 2013
}

Components: 6179 words, 1 table, 27 figures.

Keywords: Cryogenic fracturing; thermal shock; shale and tight gas reservoirs.

${ }^{1}$ Petroleum Engineering Department

Colorado School of Mines

1600 Arapahoe St.

Golden, Colorado, 80401

${ }^{2}$ Lawrence Berkeley National Laboratory

1 Cyclotron Road

Berkeley, California, 94720

(C) 2014. This manuscript version is made available under the Elsevier user license http://www.elsevier.com/open-access/userlicense/1.0/ 


\begin{abstract}
While hydraulic fracturing has revolutionized hydrocarbon production from unconventional resources, waterless or reduced-water fracturing technologies have been actively sought due to concerns arising from the heavy use of water. This study investigates the feasibility of fracture stimulation by using cryogenic fluids to create a strong thermal gradient generating local tensile stress in the rocks surrounding a borehole. Cracks form when the tensile stress exceeds the material's tensile strength. This mechanism has not been exploited in the context of stimulation and may be used to fracture reservoir rocks to reduce or eliminate water usage. This paper reports initial results from a laboratory study of cryogenic fracturing. In particular, we have developed experimental setups and procedures to conduct cryogenic fracturing tests with and without confining stress, with integrated cryogen transport, measurements, and fracture characterization. Borehole pressure, liquid nitrogen, and temperature can be monitored continuously. Acoustic signals are used to characterize fractures before and after the experiments. Cryogenic tests conducted in the absence of the confining stress were able to create cracks in the experimental blocks and alter rock properties. Fractures were created by generating a strong thermal gradient in a concrete block semi-submerged in liquid nitrogen. Increasing the number of cryogenic stimulations enhanced fracturing by both creating new cracks as well as widening the existing cracks. By comparing the cryogenic fracturing results from unstressed weak concrete and sandstone, we found that the generation of fractures is dependent on the material properties. Water in the formation expands as it freezes and plays a competing role during cryogenic cooling with rock contraction, thus is an unfavorable factor. A rapid cooling rate is desired to achieve high thermal gradient.
\end{abstract}




\section{Introduction}

Cryogenic fracturing is a concept that looks to expand and improve on traditional hydraulic fracturing technology. The concept of cryogenic fracturing rests on the idea that a large thermal gradient, perhaps caused by the evaporation of a liquified gas can induce fractures when brought into contact with a much warmer rock under downhole conditions. When liquid nitrogen $\left(\mathrm{LN}_{2}\right)$ is injected into a rock at warm reservoir temperature, heat from the rock will quickly transfer to the liquid nitrogen resulting in rapid cooling. This rapid cooling will cause the surface of the rock to contract and may fail when tension is sufficiently built up, thus creating fractures orthogonal to the contact surface of the cryogen and the rock. These newly induced fractures can be further developed using higher pressure gas generated by evaporating liquid nitrogen. Note that nitrogen has a liquid to gas expansion ratio of 1:694 at $20{ }^{\circ} \mathrm{C}\left(68^{\circ} \mathrm{F}\right)$ and atmospheric pressure.

The modern hydraulic fracturing industry relies on water-based fluids due to the general availability and low cost of water; however, this dependence upon water presents several major shortcomings. First, water can cause significant formation damage, such as clay swelling and relative permeability effects stemming from capillary fluid retention (Mazza, 1997). Secondly, water usage in large quantities may place significant stresses upon the local water supply and environments where fracturing activities occur. Finally, the downhole injection of chemicals needed in water-based fracturing programs, including slickwater and gel-based fracturing treatments has led to a contentious political climate. In contrast to hydraulic fracturing, cryogenic fracturing offers potentially greater fracturing capabilities without the issues associated with water based fracturing fluids.

King (1983) examined the use of gelled liquid carbon dioxide, instead of water, to stimulate tight gas sand formations. After performing the cryogenic fracturing, the carbon dioxide would evaporate and not cause swelling near the wellbore in water sensitive formations. Since the gelled carbon dioxide that King (1983) used was capable of carrying proppant due to its higher viscosity than pure $\mathrm{CO}_{2}$, the fractures were able to stay open. Accordingly, all the wells for which he published results experienced increased production rates (King, 1983).

Grundmann et al. (1998) treated a Devonian shale well with cryogenic nitrogen and observed an initial production rate $8 \%$ higher than the rate in a nearby offset well that had undergone traditional fracturing with nitrogen gas. Although the increased initial production rate in this research suggests the efficacy of cryogenic fracturing, there could be a number of reasons why an offset well in a shale formation might produce differently including anisotropic stress conditions and heterogeneous reservoir conditions over short distances.

McDaniel et al. (1997) conducted simple laboratory studies where coal samples were immersed in cryogenic nitrogen. The coal samples experienced significant shrinkage and fracturing into smaller cubic units, with the creation of microfractures orthogonal to the surface exposed to the 
cold fluid. The researchers found that repeated exposure cycles to the cryogen caused the coal to break into smaller and smaller pieces, or become rubblized. After 3 cycles of exposing the coal to liquid nitrogen and allowing the coal to warm to ambient temperatures again, the coal was reduced to grain size particles. McDaniel et al. (1997) also conducted field experiments with cryogenic nitrogen, and published before and after production rate data for five wells. The results were mixed: three wells showed increased production, one well showed equivalent production, and one well showed decreased production.

Cryogenic nitrogen and carbon dioxide lack significant viscosity (Fenghour et al., 1998; Rudenko and Schubnikow, 1968) and may therefore inadequately carry proppant if viscosity serves as the primary transport mechanism. Gupta and Bobier (1998) concluded that cryogenic carbon dioxide's low viscosity could not enable adequate proppant transport; however, it is possible to create a high Reynolds number by increasing the velocity of the fluid allowing for adequate transport of the proppant. The accompanying turbulence permits good transport of the proppant, at least through the wellbore to the perforations, if not through the fracture as well (Gupta and Bobier, 1998).

Some research has even shown that cryogenic fracturing may not rely as extensively upon proppant as does traditional hydraulic fracturing. The McDaniel et al. (1997) research, which demonstrated coal rubblization in laboratory experiments, suggests a self-propping mechanism. If rock undergoes sufficient breakage into small pieces at the fracture/rock interface, the formation's inability to close on this rubblized rock may enable the fracture to stay open against in-situ compressive stresses after cessation of treatment pressure.

If neither traditional proppants nor self-propping mechanisms can effectively keep the created fracture open, ultra-light weight proppants (ULWPs) may fill the gap. ULWPs are manufactured proppants that consists of a chemically hardened walnut hull core with multiple layers of epoxy resin coating acting as the outer shell (Kendrick et al., 2005). Kendrick et al. (2005) observed improved post-stimulation production in Devonian Shale wells treated with hydraulic fracturing methods using nitrogen foam fluid and ULWPs. The research shows that the majority of the wells with the ULWPs performed as good if not better than wells with traditional proppant.

Along with the possibility of drastically reducing water usage, cryogenic fracturing is a stimulation method that needs to be further studied to fully understand the opportunity it offers in the oil and gas industry. Thus, in this study, we conducted laboratory experiments using cryogenic stimulation to observe whether it can create fractures. We developed laboratory setups and procedures to simulate cryogenic stimulations in wellbore conditions. Liquid nitrogen was flowed through boreholes in unconfined rock blocks. Experiments were thoroughly monitored to measure physical parameters to understand the fundamental physical phenomena associated with cryogenic fracturing. Fracture development was characterized using acoustic signatures as well 
as visual and X-ray computed tomography (CT) inspection. We discuss expected issues in the field, and identify further studies relevant to confined conditions and field scale study.

\section{Experimental Setup}

In this section, we present the experimental setup for two submersion tests and then for two stimulation tests. We consider two cryogenic stimulation plans: thermal shock and thermal shock combined with borehole pressurization. Fracturing by thermal shock depends purely on thermal gradient around the borehole and the resulting tensile fracturing. In the fracturing by thermal shock and pressurization scenario, fractures initially generated by thermal shock are enhanced by borehole pressurization causing the fractures to widen and propagate farther. Two geometries have been investigated - cooling in boreholes in cubic blocks, and partial or total submersion of cubic blocks in liquid nitrogen.

Block semi-submersion tests: As a preliminary study, the effect of the thermal gradient on rock behavior was investigated. To apply a strong constant temperature gradient across a concrete block, an 8 inch cubic concrete block was set on supports in an open-top insulating enclosure. The enclosure was filled with liquid nitrogen up to the midline of the concrete block (Fig. 1). The liquid nitrogen level was maintained for 30 minutes and then allowed to boil off. The block was not removed until it equilibrated thermally with ambient temperature. Each side was photographed before and after the test. The images were aligned and digitally subtracted to highlight the differences.

Water-saturated block submersion test: When water becomes ice, the volume increases by $9 \%$, which is much larger than any kind of thermally-induced expansion or shrinkage in geomaterials. To investigate potential consequences of this, the behavior of water-saturated rock under cryogenic temperature was also investigated by submersion test. In this test, the concrete sample was prepared with a water to cement ratio of 0.55 , and sand to cement ratio of 2.5 . The cement was injected into an $8 " \times 8 " \times 8 "$ mold and sealed in a plastic bag. After 24 hours, the seal and mold were removed and the concrete was cured under water for 8 weeks per ASTM C192, which will maximize hydration and render the concrete very strong. The block was never removed from the water until testing, and had no visible cracks before the stimulation. In this submersion test the block was fully submerged, as show in Fig. 2.

Borehole Thermal Shock: In this test, we cooled the borehole as rapidly as possible to maximize the thermal gradient. This was done by flowing liquid nitrogen $\left(\mathrm{LN}_{2}\right)$ continuously through the borehole. The basic scheme is illustrated in Fig. 3 (the left and center part of the setup). $\mathrm{LN}_{2}$ was pumped from the Dewar by pressure difference using a liquid nitrogen withdrawal device. $\mathrm{LN}_{2}$ was transported through a vacuum-jacketed hose to the specimen, injected into the borehole, and 
then directed to an outlet. A pressure transducer was attached to monitor the borehole pressure. Because this scheme does not generate much pressure, the experiment can be applied to both confined and unconfined specimens. The experimental equipment employed cryogenic-rated transport, control, and measurement systems. Parameters including pressure inside the borehole, $\mathrm{LN}_{2}$ consumption, temperature at multiple locations, and acoustic signals were monitored in realtime. A structure that confines a packer in place was built to prevent leakage through the packer and sustain higher pressure in the borehole (Fig. 4).

Thermal Shock Combined by Borehole Pressurization: Borehole Pressurization will enhance the fractures created by the thermal shock by applying a level of pressure to the borehole during and/or after the thermal shock. One scheme of pressurization can be performed by letting existing $\mathrm{LN}_{2}$ in the borehole evaporate while shutting off all of the inlet and outlet valves. Another is by forcing pressurized nitrogen gas into the borehole (right side of Fig. 3). While high borehole pressurization is possible for confined specimens confined by triaxial loading equipment, unconfined specimens cannot sustain much borehole pressure (rock splitting was observed in weak concrete due to pressurization).

Packer Placement: Packers were used to accommodate inlet and outlet tubing and seal the borehole from the outside. At low borehole pressure in unconfined specimens, we attached a packer to the top of a borehole with epoxy and then applied loading using the confining device, depending on the expected level of pressure inside the borehole (Fig. 4). Springs located on the bolts were used to accommodate specimen contraction due to thermal contraction while still applying almost the same stress on the packer. This device was used for our tests with unconfined specimens.

\section{Experimental Results}

\subsection{Semi-submersion experiment}

In the first submersion experiments, the concrete block was semi-submerged to induce a strong temperature gradient along the $\mathrm{LN}_{2}-\mathrm{GN}_{2}$ contact line (Fig. 1). Fig. 5 shows the results from image subtraction before and after the cryogenic treatment. The difference image for the top and bottom (Faces 5 and 6) do not show any fractures. The four vertical faces (Faces 1 through 4) that were semi-submerged show a fracture along the center all the way around the block (light shaded crack). This indicates that the block was fractured due to the application of the thermal gradient. During the 30+ minute test, there were no obvious indications of block fracturing such as large visible cracks or audible cracking sounds. Following the test, the block was CT scanned using a modified G.E. Lightspeed 16 medical CT scanner. Fig. 6 shows a vertical cross section 
indicating the presence of a fracture (darker) emanating from both sides and progressing towards the center of the block.

\subsection{Full submersion test of a water-saturated cement sample}

In the full submersion experiment conducted with the water-saturated cement sample (Fig. 2), all major cracks were created near edges during the cryogenic stimulation (Fig. 7). In this case, the ice, which is heavily interconnected through pores, was expanding against mineral (cement and sand) matrix. Thus the outer layer of the block exposed to $\mathrm{LN}_{2}$ experienced water freezing and expanding, whereas the inner block did not. The outer layer expanded laterally, resulting in shear fractures parallel to the exposed surfaces (Fig. 8) (Kneafsey et al., 2011). If cracks were formed from rock contraction (without the effect of ice), more cracks should be located away from and perpendicular to the edges. The block bottom was in direct contact with the Styrofoam container limiting $\mathrm{LN}$ access resulting in the absence of cracks there.

Simple calculations may help explain the competition between expansion of the ice matrix and contraction of the mineral (cement) network. The volumetric thermal expansion coefficient of concrete $\gamma$ (at $20^{\circ} \mathrm{C}$ ) is $36 \times 10^{-6} /{ }^{\circ} \mathrm{K}$. Assuming $\gamma$ is constant throughout the temperature range, the volume reduction due to a cryogenic temperature change would be:

$$
\text { Volume reduction }(\%)=200 \mathrm{~K} \times 36 \times 10^{-6} /{ }^{\circ} \mathrm{K} \times 100(\%)=0.72 \%
$$

Upon phase change from water to ice, the volume increases by $9 \%$. Assuming the porosity of concrete is $20 \%$, the overall resulting volume change becomes:

$$
\text { Overall volume change }(\%)=(9 \%) \times 0.2-(0.72 \%) \times 0.8=1.2 \% \text { (expansion })
$$

There may be other complicating factors such as movement of water molecules within the block and outside during the freezing process. However, the movement of water to the outside will be negligible because the surface water will be immediately frozen upon $\mathrm{LN}_{2}$ submersion.

\subsection{Borehole cryogenic stimulation of unconfined specimens}

Two $8 \times 8 \times 8$ inch $^{3}$ block specimens were cryogenically stimulated by flowing $\mathrm{LN}_{2}$ through a borehole made into the specimen. A summary of these tests is listed in Table 1. One concrete block and one sandstone block were used in these tests. Measurements included pressure, temperature, acoustic waves, $\mathrm{LN}_{2}$ consumption, and CT scanning. For all cases, specimens were photographed before and after cryogenic stimulations. 


\subsubsection{Thermal shock on the concrete specimen}

Two thermal shock experiments were performed on a concrete specimen without pressurization. The cement concrete block was air-cured for 5 weeks after being contained in the mold for 24 hours, resulting in relatively low strength. Fig. 9 shows the experimental setup that was used for the thermal shock experiment on concrete. $\mathrm{LN}_{2}$ was flowed from the Dewar to the specimen borehole through the vacuum jacketed tube and insulated stainless steel tubes. The borehole was open to the air through a vent and relatively warm $\mathrm{N}_{2}$ flowed out to the atmosphere. There was no significant pressure buildup inside the borehole because $\mathrm{N}_{2}$ flowed freely into the atmosphere. In this $1^{\text {st }}$ test, the packer was not confined and loosely fastened to top of the borehole, so $\mathrm{LN}_{2}$ leaked through packer/concrete interface and out of the insulation, making the thermal shock less effective.

The $2^{\text {nd }}$ test was performed on the same concrete block that was used for the $1^{\text {st }}$ test using the structure shown in Fig. 4 and Fig. 9, designed to withstand borehole pressure up to 500psia. For this experiment, we only used a low pressure caused by vaporization $(\sim 10 \mathrm{psi})$. A pressure transducer was attached to monitor the borehole pressure, and a scale was used to record $\mathrm{LN}_{2}$ consumption. A set of S-wave acoustic sensors were mounted at locations on Faces 2 and 4 to monitor the wave signatures. A pulser and an oscilloscope were used to generate and record signals.

We observed that devices and materials in the setup performed well through the testing. There were no leaks through the packer/rock interface. The epoxy seal and stainless steel packer with tubes connected all remained intact under the cryogenic temperature conditions. The cryogenrated insulation and the thermocouple's plastic insulation coat remained functional. The carbon steel plates performed at low temperatures $\left(\sim-30^{\circ} \mathrm{C}\right)$. One reason why these were undamaged is that, unlike the borehole environment, temperature propagation was slower in the surrounding environment, preventing sharp thermal gradient. Another reason could be that the small volume of the material does not create enough contraction to fail the materials and/or interfaces. The block surfaces started to form frost once the temperature of the surface fell well below the waterfreezing point. The frost was first noticed at the top and sides of the specimen, which are closer to the borehole.

\section{$\underline{\text { Cracks }}$}

Before the $1^{\text {st }}$ thermal shock, there were no visible cracks near or inside the borehole. After the thermal shocks, several noticeable cracks were found. Major cracks were visible from the top of the borehole (Fig. 10). There were some pre-existing micro-cracks on the block surfaces before the thermal shock due to the natural shrinkage of concrete (Fig. 11a). Note that the dark spots are stains from the coupling material used to facilitate the transmission of acoustic energy. After the thermal shock, new cracks were generated and even visible on the surfaces, and the existing cracks became wider (see Fig. 11 for comparison). Particularly, there was a relatively small 
number of cracks at the bottom before applying the cryogen; however, many new cracks were created after the cryogen applications.

During the $2^{\text {nd }}$ thermal shock, significant gas and liquid nitrogen permeation was observed through fractures that might have been opened up at the later stage of the experiment. The amount of leakage was dependent on the release rate from the dewar.

The specimen was scanned using an X-ray CT (Toshiba Aquilion 64). The maximum resolution of the images from the scanner is $0.3 \mathrm{~mm} \times 0.3 \mathrm{~mm} \times 0.3 \mathrm{~mm}$. Thus, the CT images can only be used to detect major cracks. The CT images show that there are more fractures near the outer surfaces than the inside of the specimen. X-ray slices (a few examples are given in Fig. 12) show that cracks distributed near the exposed surfaces diminish as they move toward the inside of the specimen. There are also a few internal cracks that are not connected to any of the exposed surfaces.

\section{Temperature, pressure, and liquid nitrogen consumption}

Temperature was measured at seven locations in the specimen and the setup using thermocouples (TC) (Fig. 13). TC \#2 (in black) was suspended inside the borehole, while TC \#1 was attached to the borehole wall surface. Temperatures at the carbon steel plate (TC \#4) and near the pressure transducer (TC \#3) were monitored to protect the plates and the sensor. The temperature evolution during the experiment at the seven locations is plotted in Fig. 14c. Throughout the test, the temperature difference between the inside of the borehole and the block face was observed to be large. It is also observed that cooling at the borehole surface was slower due to a phenomenon called the Leidenfrost effect. Due to a very large temperature difference between the rock surface and the boiling point of the fluid, the liquid nitrogen immediately boils at near contact with the surface, creating a vapor cushion, which has a much lower thermal conductivity than the $\mathrm{LN}_{2}$, thus delaying the heat transfer to the rock surface. Due to leakage of $\mathrm{GN}_{2}$ and $\mathrm{LN}_{2}$ through the created fractures, we had to from time to time partially close and then open the dewar valve to control the leaking. The spikes in the plots are where the $\mathrm{LN}_{2}$ valve was closed temporarily. The temperature inside the borehole was sensitive to valve operations and the temperature increased rapidly when the $\mathrm{LN}_{2}$ supply was stopped (Fig. 14c).

The amount of $\mathrm{LN}_{2}$ leaving the dewar was monitored using a scale (Fig. 14a). The nonlinear $\mathrm{LN}_{2}$ consumption vs. time before the first partial closure shows that strong vaporization occurred at the beginning, which blocked the flow of $\mathrm{LN}_{2}$. Then as the system cooled down, the flow rate of $\mathrm{LN}_{2}$ increased. Pressure was generated due to vaporization in the borehole and along transport lines. In the thermal shock test setup, pressure inside the borehole was practically the same as the pressure inside the dewar (about 5 10 psi). The changes in pressure were very responsive to the opening and partial closing of the valve of the dewar (Fig. 14b). 


\section{Acoustic signatures}

The characteristics of acoustic waves propagating through the medium depend on the mechanical properties of the medium. In particular, the wave velocity in jointed rock masses is a function of the density of cracks (or joint spacing) and thus has been modeled (Cha et al., 2009) as follows:

$$
V_{S}=\sqrt{\frac{G_{e q}}{\rho}}=\sqrt{\frac{1}{\rho}\left(\frac{k_{S} S G}{k_{S} S+G}\right)}
$$

where $V_{S}, k_{S}, G, \rho$, and $S$ are shear wave velocity, shear joint stiffness, shear modulus of intact part, rock mass density, and joint spacing respectively. This equally applies to the (compressional) P-wave velocity. When other properties such as intact rock properties, density, and joint stiffness are the same, the wave velocity can be used as a monitoring tool to characterize crack generation. Geomaterials are natural low-pass filters of acoustic waves due to inherent discontinuities such as granular discreteness and cracks. Acoustic waves propagating through cracked media have their high frequency content filtered.

The differences in the acoustic signatures before and after the cryogenic stimulation were investigated by acoustic measurements before and after the tests using $\mathrm{P}$ and $\mathrm{S}$ ultrasonic transducers. Acoustic waves were also monitored during the cryogenic stimulation by mounting $\mathrm{S}$ transducers to the specimen surfaces. Fig. 15 shows the locations for the acoustic measurements before and after the cryogen stimulation. Acoustic signals were measured between Faces $1 \& 3$ and $2 \& 4$ (faces opposite each other). For each face set, the acoustic measurements were conducted at the 12 locations. In this work, we focus on $\mathrm{P}$ and $\mathrm{S}$ wave velocities and amplitudes. P-wave signals between Faces 1 and 3 are shown in Fig. 16.

In Fig. 16a, early parts of elastic wave signals are presented with their amplitudes normalized so we can focus on changes in the arrival time and in the waveforms. At most measurement locations, arrivals were delayed after cryogenic stimulation, which means that the wave velocity decreased as a result of the cryogenic stimulation, and waveforms have changed. The characteristic of acoustic signatures approximately corresponds to density of the surface cracks. For example, the acoustic signals at location 12 were the least changed in terms of the arrival time, and we also observed that the surface around location 12 was the least cracked. In Fig. 16b, the signals show early times near the arrivals, but the original amplitudes were kept so that one can observe the changes in the amplitudes. Wave amplitudes reduced significantly after the thermal shock (except for Location 12). Signals compared with their full range of the measurements show that the global frequency of the signals became lower after completing the cryogenic fracturing at most locations.

The changes in P-wave velocities are summarized in Fig. 17. Lower velocities near the edges (\#1 $\&$ 8) and center (\#4 \& 5) show the effects of boundaries and borehole cavity. The wave velocities decreased by $7 \sim 13 \%$ due to the application of thermal shocks. 


\subsubsection{Cryogenic stimulations on the sandstone specimen}

Cryogenic stimulation experiments were performed on a sandstone specimen obtained from a quarry in Denver Colorado. Multiple tests were conducted due to inefficient thermal shock (the first two instances) and more resistance of the sandstone to thermal shock than the previous concrete specimen. The list of thermal stimulations and conditions applied on the sandstone specimen is documented in Table 1 . Note that in the $1^{\text {st }}$ and $2^{\text {nd }}$ thermal shocks, cold nitrogen gas was released instead of $\mathrm{LN}_{2}$ due to a malfunction of the withdrawal device. This problem was remedied prior to the $3^{\text {rd }}$ thermal shock. Pressurization was applied to the specimen during the $4^{\text {th }}$ test in addition to thermal shocks. Because there were no apparent fractures and no leaking of $\mathrm{GN}_{2}$ and $\mathrm{LN}_{2}$ through the fractures, the dewar valve was opened fully throughout the experiment in all tests.

\section{First three thermal shocks without pressurization}

Due to withdrawal device malfunctions, nitrogen injection into the borehole was in the gas form for the first two experiments. This was indicated by the temperatures in the borehole, which were significantly higher than $\mathrm{LN}_{2}$ boiling point. We did not observe any drops of $\mathrm{LN}_{2}$ from the outlet either. The temperature data did not show the Leidenfrost effect, which is yet another indication of lacking $\mathrm{LN}_{2}$.

The pressure inside the borehole basically followed a trend similar to the pressure inside the dewar, except that the pressure inside the borehole was lower by about 1 psi. In this test, the release valve to the dewar was opened completely until the end of the test without any partial or temporal closure. High-frequency fluctuations of the temperature data were also indicated by fluctuations of flow sound at the outlet, which is related to the pressure fluctuation in the borehole.

No noticeable cracks were generated after the first two thermal shocks, possibly due to slower reduction of temperature, higher final temperature, lower brittleness, and the higher strength of the sandstone block.

At the $3^{\text {rd }}$ thermal shock, the $\mathrm{LN}$ withdrawal device was improved and liquid nitrogen was injected into the borehole. Acoustic measurements were performed after the $3^{\text {rd }}$ thermal shock to monitor alterations in the acoustic wave transmission properties due to the thermal shocks. The temperature data showed more immediate temperature reduction compared with the two previous experiments as well as the Leidenfrost effect, which are indications of $\mathrm{LN}_{2}$ presence in the borehole. 


\section{The $4^{\text {th }}$ thermal shock $\left(\mathrm{LN}_{2}\right)$ and borehole pressurization}

The $4^{\text {th }}$ test was set up to pressurize the borehole. This was done by adding cryogenic-rated valves, a pressure relief valve, an accumulator, and a compressed nitrogen cylinder (Fig. 18 and Fig. 19). The pressure release valve was set to 275 psi so that the pressure inside the borehole would not exceed that pressure. The reason for this low set pressure was that geomaterials are generally weak under tension and cannot sustain much internal pressure when they are not confined. At the end of the test, no noticeable cracks were found on the surfaces of the block by visual inspection.

\section{Pressure, temperature, and $\mathrm{LN}_{2}$ consumption $\left(4^{\text {th }}\right.$ test $)$}

After the thermal shock, two different borehole pressurizations were attempted. One was by natural vaporization of liquid nitrogen in a closed system (Fig. 20a). The other was by pressurizing the borehole using compressed nitrogen gas (Fig. 20b). It was observed that $\mathrm{LN}_{2}$ vaporization caused the pressure to increase up to $250 \mathrm{psi}$ and dropped rapidly following a pressure decay curve (Fig. 21b). This is because nitrogen (most likely at a gas state) in the borehole escaped through the sandstone at a fairly high rate by permeation. This significant permeation rate was also indicated from air permeation tests performed on the sandstone block prior to the application of thermal shocks.

The temperature inside the borehole increased rapidly as the borehole was pressurized (both forced pressurization and self-pressurization) (Fig. 21). This temperature increase occurred from gas compression and heat transfer near the borehole. While the temperature increased when the $\mathrm{LN}_{2}$ supply discontinued, the temperature increments were further accelerated by the pressurization. Due to the lengthy duration of the experiment (75 minutes), even the temperatures of the surfaces of the rock became very low (as low as $-50^{\circ} \mathrm{C}$ ) at the end of experiments. In addition to conductive heat transfer, flow of cold nitrogen gas through the sandstone also contributed to the reduction of the outer surface temperature.

\section{Acoustic measurements}

The $\mathrm{P}$ and $\mathrm{S}$ wave signatures before thermal shock, after the $3^{\text {rd }}$ test, and after the $4^{\text {th }}$ test are compared in Figure 22. The arrivals of $\mathrm{P}$ and $\mathrm{S}$ waves between Faces 1 and 3 with normalized amplitude are shown in Fig. 22. The velocities changed, but in relatively small magnitude considering the number of stimulations performed. This shows that sandstone is more resistant to cryogenic stimulations compared to the cement. This may be because the thermal gradient was lower as a result of cold gas permeating through the sandstone, or that the thermal contraction relative to the strength and ductility of the sandstone was not as great. Although we did not see visible cracks on the block surfaces and in the borehole, velocity changes show that there were cracks generated within the block perhaps indicating fractures in the inter-grain cement. Wave velocity decreased by $2.5 \sim 6 \%$ for the P-waves, and 3.5 6.3\% for the $\mathrm{S}$-waves after the stimulations (Fig. 23 and Fig. 24). The velocity increment due to the $4^{\text {th }}$ cryogenic stimulation as 
the thermal shocks and pressurizations turns out to be relatively small, which indicates that the effect of the pressurization is negligible at this low pressure level and permeable sandstone. The decrease or increase of velocities toward a certain direction indicates that internal mechanical properties are directional (Fig. 23 and Fig. 24).

\section{Bubble leakage test}

We found that a leak hole/crack was generated during the $2^{\text {nd }}$ pressurization (forced pressurization) at the packer/rock interface by a hissing sound as well as by the pressure data (Fig. 21b). After the test, a bubble agent was used to detect the leak. In order to do this, the borehole was pressurized to about 50 psi using compressed air. The leak hole created during the $2^{\text {nd }}$ pressurization may be seen in Fig. 25a at the location of the largest foam accumulation. Then the bubble agent was applied all over the top surface and Face 1 to observe permeation pattern at the block surfaces. We observed that there are several localized permeation spots (or "leaking holes") as shown in Fig. 25. The bubble leakage test showed that permeation through the stone was not homogeneous even in a rock that appears to be intact and homogeneous; there were invisible pathways (cracks, holes, or simply more permeable regions) that allowed preferential permeation of air/fluid.

\section{Leidenfrost effects and formation water related issues}

Clearly, there are many challenges to overcome before $\mathrm{LN}_{2}$ can be used effectively as a fracturing fluid, e.g. transportation of $\mathrm{LN}_{2}$ to the target reservoirs, use of proppants with $\mathrm{LN}_{2}$, and high heat flux from rock masses. Here we discuss two specific issues identified from this laboratory study - the Leidenfrost effects and the issue of formation water.

\subsection{Leidenfrost effect - slower cooling rate}

The Leidenfrost effect happens anywhere when liquid is in near contact with a surface significantly hotter than the liquid's boiling point. It slows down heat transfer to the rock by creating a vapor cushion, which has very low thermal conductivity, and thus may inhibit a sharp thermal gradient hindering fracture propagation.

An experiment was performed to observe the Leidenfrost effect at the rock- $\mathrm{LN}_{2}$ interface. Two Lyons sandstone blocks with roughly the same dimensions $(3 " \times 3 " \times 4 ")$ were used for the test (Fig. 26a). Two temperature sensors were attached to each block to monitor temperatures as they were submerged into $\mathrm{LN}_{2}$. Another temperature sensor was placed directly in the liquid nitrogen without touching any surfaces (Fig. 26b). Before the submersion, Block 1 was heated to $120{ }^{\circ} \mathrm{C}$, while Block 2 was at ambient temperature. Upon submersion, $\mathrm{LN}_{2}$ violently boiled off at the interface of the blocks and liquid nitrogen, and the temperatures at the thermocouples (Fig. 26b) indicated the presence of an insulating gas layer because they did not rapidly drop to the boiling 
$\mathrm{LN}_{2}$ temperature (Fig. 27). The block with the higher temperature took a longer time to reach the temperature of $\mathrm{LN}_{2}$ at its surface as it sustained the boiling (and Leidenfrost effect) longer (Fig. 27). In spite of the Leidenfrost effect, it is observed that the temperature dropped fairly rapidly to a certain temperature (about $-120{ }^{\circ} \mathrm{C}$ in these tests) which is still significantly warmer than the normal $\mathrm{LN}_{2}$ boiling temperature $\left(-196{ }^{\circ} \mathrm{C}\right)$. Although the temperatures recorded from the thermocouples at the block surface reached the temperature of liquid nitrogen in about 7 minutes, $\mathrm{LN}_{2}$ continued to boil at the interfaces with gradually decreasing magnitude.

There are potential methods to reduce the Leidenfrost phenomena. The use of slush nitrogen, which is a mixture of solid nitrogen and liquid nitrogen, is a relatively proven method to increase the cooling rate (Sansinena et al., 2012), and apparatuses for producing slush of nitrogen have been devised (Kawamura et al., 2007; Machida et al., 2009). Similarly, mixing proppants in liquid nitrogen as a solid suspension might help reduce the Leidenfrost effect, and this would be advantageous as proppant may be needed to keep the fractures open. As pressure increases, the Leidenfrost effect occurs at a relatively higher temperature (Temple-Pediani, 1969). Therefore, at higher pressures, the Leidenfrost effect will diminish earlier after $\mathrm{LN}_{2}$ application. Temperatures of the subsurface environments where fracturing is desired need to be considered as they can be very high. The Leidenfrost effect can also be decreased by creating roughness on the surfaces (Bernardin and Mudawar, 1999).

\subsection{Formation water saturation}

From the full submersion test of a water-saturated cement block, we learned that water saturation is an important factor in determining the thermal expansion / contraction of the formation. Depending on the water saturation level in formations, which varies greatly, the presence of water will weaken the driving force of cryogenically induced tensile fractures. Near the wellbore, water content may be high due to prior exposures to drilling and completion fluids. Volume expansion by freezing water is likely to weaken tensile stress or even create circumferential compression depending on water saturation. In addition to being an unfavorable condition for tensile failure, the compressional stress may also lead to wellbore failure and stability issues. On the other hand, frozen water on the surface or near the surface of the wellbore may inhibit nitrogen permeation into the formation and lead to stronger temperature gradient. Thus, the presence of water in or near the wellbore is likely to create a complicated situation. We will conduct more experiments in the future to carefully study its effect.

Finally, it is worthwhile to note that in this study concrete was used as a surrogate for specimen as it is easy to mold to form desired shapes and as it is a common engineering material. However, concrete and natural rocks are different in many ways. Depending on the mix ratio and the curing quality, concrete can have much residual water after hydration that cannot be easily removed unless by high heating. Water is trapped in isolated micropores, and up to $15 \%$ of water by weight can be removed by heating $\left(100{ }^{\circ} \mathrm{C}\right)$ of a fully cured air-dried $100 \%$ cement concrete 
(tested in our lab). In our study, as thermal shocks were applied to the borehole of the concrete specimen, more fractures were observed on the outer surfaces of the block than inside the borehole, which is counter-intuitive. It may be possible that this is caused by the phase change of residual water in the micropores upon thermal shocks, which aided the fracturing of the outer surfaces.

\section{Summary and conclusions}

This paper reports a laboratory study of cryogenic fracturing. We designed experimental setups and laboratory procedures for cryogenic stimulation. The ability of liquid nitrogen to create fractures was tested in submersion tests and borehole stimulation experiments, and fracture assessments were made by visual inspection, X-ray CT, and acoustic signatures. The velocities and amplitudes of acoustic waves were sensitive to rock properties thus we were able to detect changes in properties that were not visible. CT images identified spatial distribution of major cracks. Measurement of both temperature and pressure data during stimulation gave us opportunities to monitor the state of the stimulating fluid as well as to assess the efficiency of the heat transfer process.

The cryogenic stimulations conducted in our study were able to create cracks in the rock blocks and alter rock properties. Fractures were created by generating a strong thermal gradient in a concrete block half-submerged in $\mathrm{LN}_{2}$. Application of liquid nitrogen to boreholes in the center of cement and sandstone specimens generated mixed results. For the cement block, repeated thermal shock generated visible fractures, the signatures of which were easily picked up by the acoustic measurements. Increasing the number of liquid nitrogen applications to boreholes enhances fracturing by both creating new cracks as well as widening the existing cracks. For the sandstone block, after two thermal shocks with gaseous nitrogen and two more thermal shocks with liquid nitrogen combined with elevated pressure (one from pressure buildup due to evaporation and another from an external pressurized nitrogen source), no visible fractures were detected. Clearly, the generation of fractures was highly dependent on material properties. Results from acoustic tests, however, suggest that there were invisible fractures generated inside the sandstone block.

To maximize the cooling rate, means to alleviate the Leidenfrost effect need to be sought. Immediate $\mathrm{LN}_{2}$ flooding is equally desired, which can be helped by efficient insulation and transportation. The freezing of water in formations plays a competing role with contraction of the rock but also forms a barrier to permeation near a wellbore; the effect of these competing factors on cryogenic fracturing should be further assessed. Although many unconventional gas formations have low water saturations, near the wellbore water saturation can be significant from prior drilling and completion operations. Borehole pressurization due to $\mathrm{LN}_{2}$ vaporization in a 
closed system may not generate sufficient pressure to propagate the fractures due to the limited $\mathrm{LN}_{2}$ quantity and rate of vaporization. Gas permeation also reduces the buildup of pressure. Thus, external pressure may still be needed to propagate the cryogenically induced fractures.

Several topics that require further studies have been identified in this laboratory study. Cryogenic fracturing at reservoir stress levels by thermal shock, and the added effect of borehole pressurization are still poorly understood. The effect of stress level and stress anisotropy on the characteristics of cryogenic fracturing can be investigated by using a triaxial loading system. The effects of various material properties on cryogenic fracturing behavior should be thoroughly investigated. A full dimensional analysis considering all the relevant parameters will serve as a frame of understanding and will guide the scaling up of laboratory studies to potential field applications.

\section{Acknowledgements}

Support for this research was provided by RPSEA (Research Partnership to Secure Energy for America). We thank Manika Prasad for helping in the acoustic measurements, and Mike Brown for providing machined parts. In addition, we thank the Fracturing, Acidizing, Stimulation Technology Consortium (FAST) and Bryant Morris and Shannon Osterhout of the Pioneer Natural Resources for their support of the study. Timothy Kneafsey was supported by the

Assistant Secretary for Fossil Energy, Office of Oil and Natural Gas of the U.S. Department of Energy under Contract No. DE-AC02-05CH11231. 


\section{References}

Bernardin, J.D. and Mudawar, I., 1999. The Leidenfrost Point: Experimental Study and Assessment of Existing Models. Journal of Heat Transfer, 121(4): 894-903.

Cha, M., Cho, G.C. and Santamarina, J.C., 2009. Long-wavelength P-wave and S-wave propagation in jointed rock masses. Geophysics, 74(5): E205-E214.

Fenghour, A., Wakeham, W.A. and Vesovic, V., 1998. The Viscosity of Carbon Dioxide. Journal of Physical and Chemical Reference Data, 27(1): 31-44.

Grundmann, S.R., Rodvelt, G.D., Dials, G.A. and Allen, R.E., 1998. Cryogenic Nitrogen as a Hydraulic Fracturing Fluid in the Devonian Shale, SPE Eastern Regional Meeting. Society of Petroleum Engineers, Pittsburgh, Pennsylvania.

Gupta, D.V.S. and Bobier, D.M., 1998. The history and success of liquid $\mathrm{CO}_{2}$ and $\mathrm{CO}_{2} / \mathrm{N}_{2}$ fracturing system. SPE, 40016.

Kawamura, K. et al., 2007. Apparatus for producing slush nitrogen and method for producing the same. Google Patents.

Kendrick, D., Puskar, M. and Schlotterbeck, S., 2005. Ultralightweight Proppants: A Field Study in the Big Sandy Field of Eastern Kentucky, SPE Eastern Regional Meeting.

King, S.R., 1983. Liquid CO2 for the Stimulation of Low-Permeability Reservoirs, SPE/DOE Low Permeability Gas Reservoirs Symposium.

Kneafsey, T.J. et al., 2011. Examination of core samples from the Mount Elbert Gas Hydrate Stratigraphic Test Well, Alaska North Slope: Effects of retrieval and preservation. Marine and Petroleum Geology, 28(2): 381-393.

Machida, A., Hattori, K. and Matsuo, K., 2009. Method and apparatus for producing slush nitrogen. Google Patents.

Mazza, R.L., 1997. Liquid CO2 improves Fracturing. Hart’s Oil and Gas World, 22.

McDaniel, B., Grundmann, S., Kendrick, W., Wilson, D. and Jordan, S., 1997. Field applications of cryogenic nitrogen as a hydraulic fracturing fluid, SPE Annual Technical Conference and Exhibition.

Rudenko, N.S. and Schubnikow, L.W., 1968. The Viscosity of Liquid Nitrogen, Carbon Monoxide, Argon and Oxygen as a Function of Temperature, NASA-TT-F-11-868, 1-5.

Sansinena, M., Santos, M.V., Zaritzky, N. and Chirife, J., 2012. Comparison of heat transfer in liquid and slush nitrogen by numerical simulation of cooling rates for French straws used for sperm cryopreservation. Theriogenology, 77(8): 1717-1721. 
Temple-Pediani, R.W., 1969. Fuel Drop Vaporization under Pressure on a Hot Surface. Proceedings of the Institution of Mechanical Engineers, 184(1): 677-696. 
Table 1 List of cryogenic stimulation experiments

\begin{tabular}{|l|l|l|c|c|}
\hline Specimen & \multicolumn{1}{|c|}{$\begin{array}{c}\text { Cryogenic } \\
\text { stimulation }\end{array}$} & \multicolumn{1}{|c|}{ Measurements } & $\begin{array}{c}\text { Cryogen } \\
\text { (Amount) }\end{array}$ & Duration \\
\hline \multirow{4}{*}{$\begin{array}{l}\text { Cement } \\
\text { concrete }\end{array}$} & $\begin{array}{l}1^{\text {st }} \text { thermal shock } \\
\text { (unconfined packer) }\end{array}$ & $\begin{array}{l}\text { T, Acoustic (before, } \\
\text { during, after) }\end{array}$ & $\begin{array}{c}\mathrm{LN}_{2} \\
(\mathrm{~N} / \mathrm{A})\end{array}$ & $52 \mathrm{~min}$. \\
\cline { 2 - 6 } & $2^{\text {nd }}$ thermal shock & $\begin{array}{l}\mathrm{T}, \mathrm{P}, \text { Acoustic (before, } \\
\text { during, after), } \mathrm{LN}_{2} \text { weight }\end{array}$ & $\begin{array}{c}\mathrm{LN}_{2} \\
(7 \mathrm{~kg})\end{array}$ & $21 \mathrm{~min}$. \\
\hline \multirow{5}{*}{ Sandstone } & $1^{\text {st }}$ thermal shock & $\begin{array}{l}\mathrm{T}, \mathrm{P}, \text { Acoustic (before) } \\
\mathrm{LN}_{2} \text { weight }\end{array}$ & $\begin{array}{c}\mathrm{GN}_{2} \\
(12.8 \mathrm{~kg})\end{array}$ & 57 min. \\
\cline { 2 - 6 } & $2^{\text {nd }}$ thermal shock & $\mathrm{T}, \mathrm{P}, \mathrm{LN}$ weight & $\begin{array}{c}\mathrm{GN}_{2} \\
(14 \mathrm{~kg})\end{array}$ & 73 min. \\
\cline { 2 - 6 } & $3^{\text {rd }}$ thermal shock & $\begin{array}{l}\mathrm{T}, \mathrm{P}, \text { Acoustic (after), } \\
\mathrm{LN} 2 \text { weight }\end{array}$ & $\begin{array}{c}\mathrm{LN}_{2} \\
(15.4 \mathrm{~kg})\end{array}$ & $70 \mathrm{~min}$. \\
\cline { 2 - 6 } & $\begin{array}{l}4^{\text {th }} \text { thermal shock } \\
+ \text { Pressurizations }\end{array}$ & $\begin{array}{l}\mathrm{T}, \mathrm{P}, \text { Acoustic (after), } \\
\mathrm{LN}_{2} \text { weight }\end{array}$ & $\begin{array}{c}\mathrm{LN}_{2} \\
(13.8 \mathrm{~kg})\end{array}$ & $160 \mathrm{~min}$. \\
\hline
\end{tabular}

*Note that $\mathrm{T}, \mathrm{P}$, and $\mathrm{GN}_{2}$ represent temperature, pressure, and gaseous nitrogen respectively. 
Figures

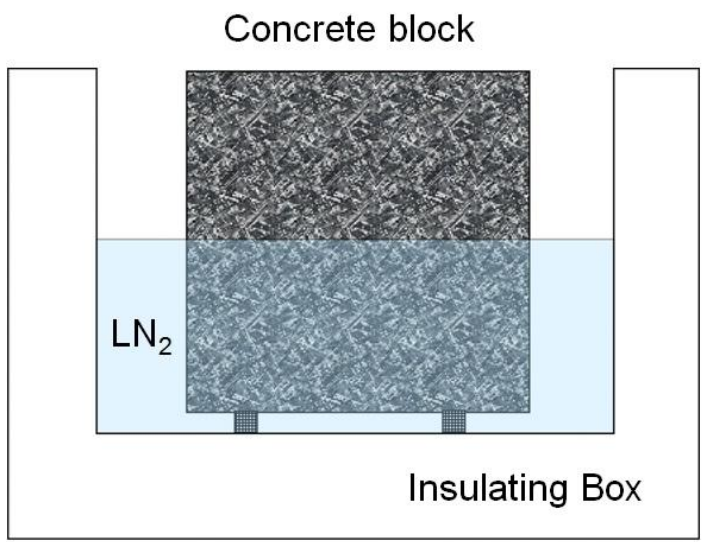

Fig. 1 Setup for semi-submersion test. 
(a)

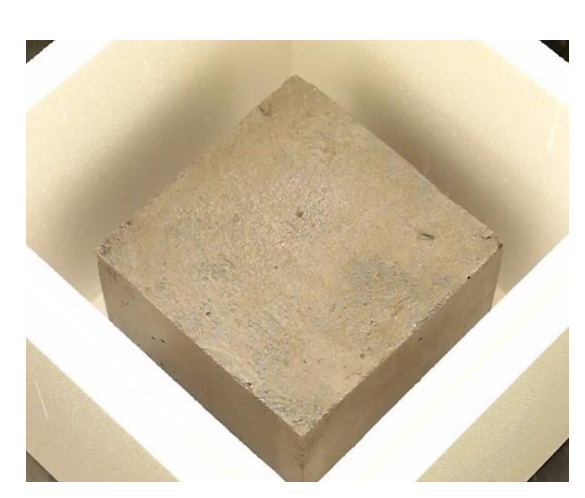

(b)

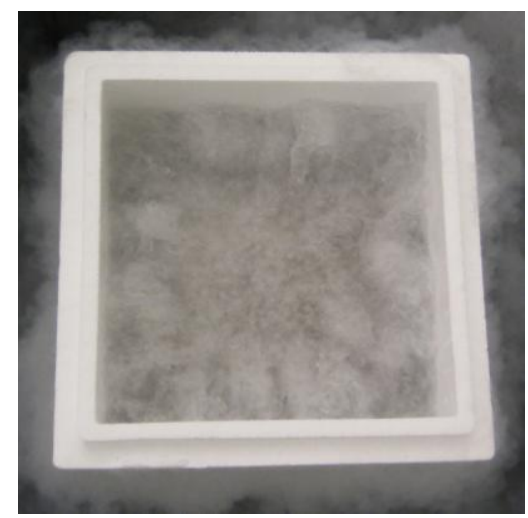

Fig. $2 \mathrm{LN}_{2}$ submersion test (a) The water-saturated concrete cube placed inside a Styrofoam container (b) Violent $\mathrm{LN}_{2}$ film boiling at the interface between $\mathrm{LN}_{2}$ and the block surfaces. 


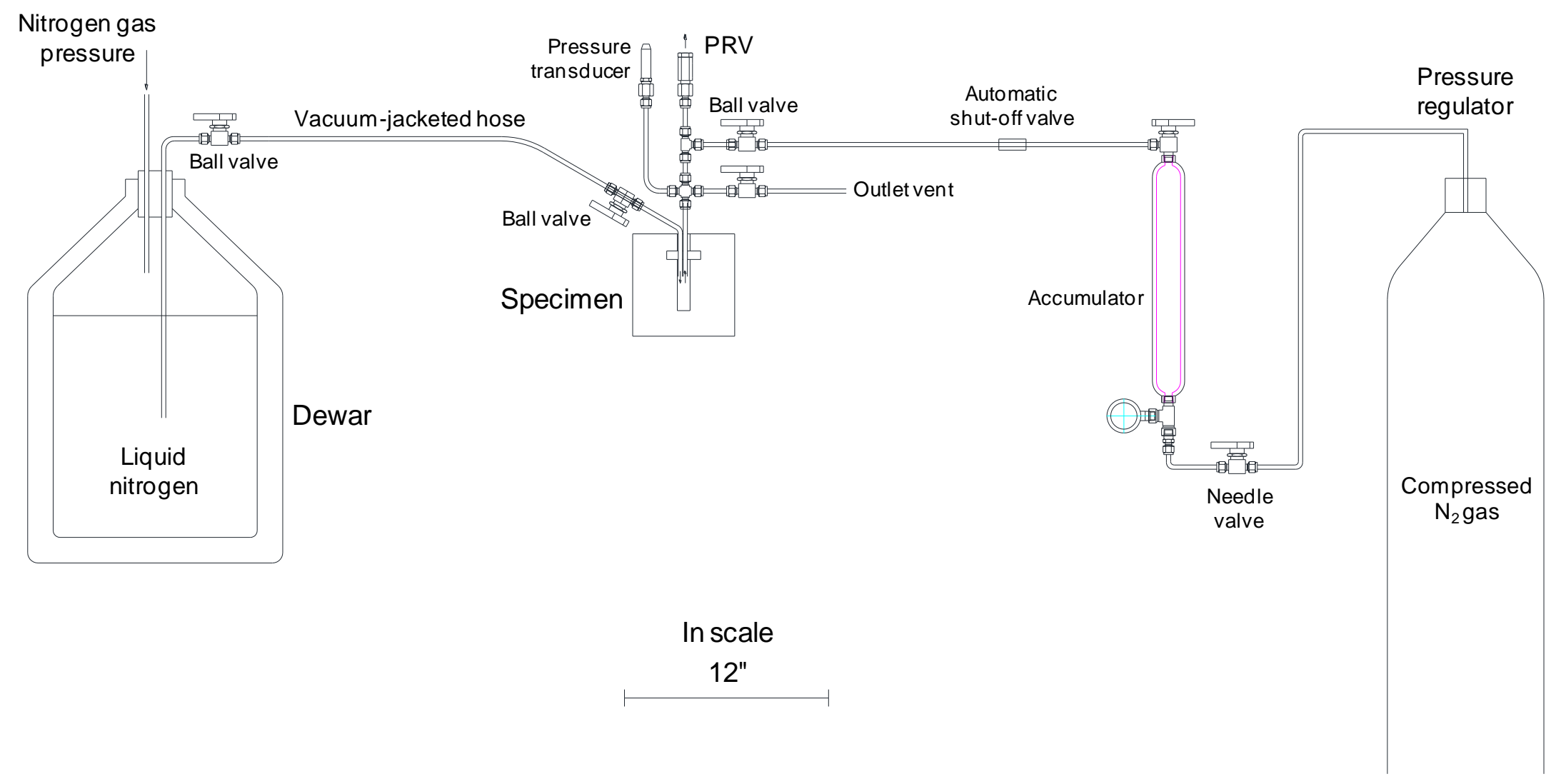

Fig. 3. Overall schematic for borehole cryogenic stimulation experiments (for both thermal shock and thermal shock followed by pressurization). 


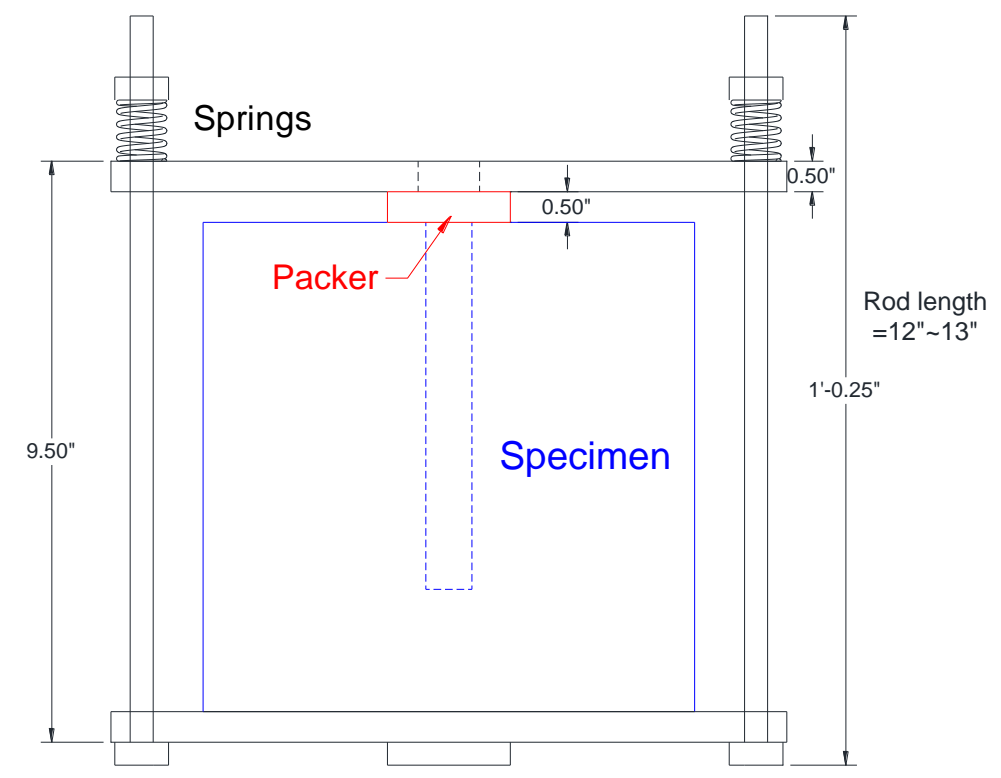

Fig. 4 Packer installation by using a confining structure. 


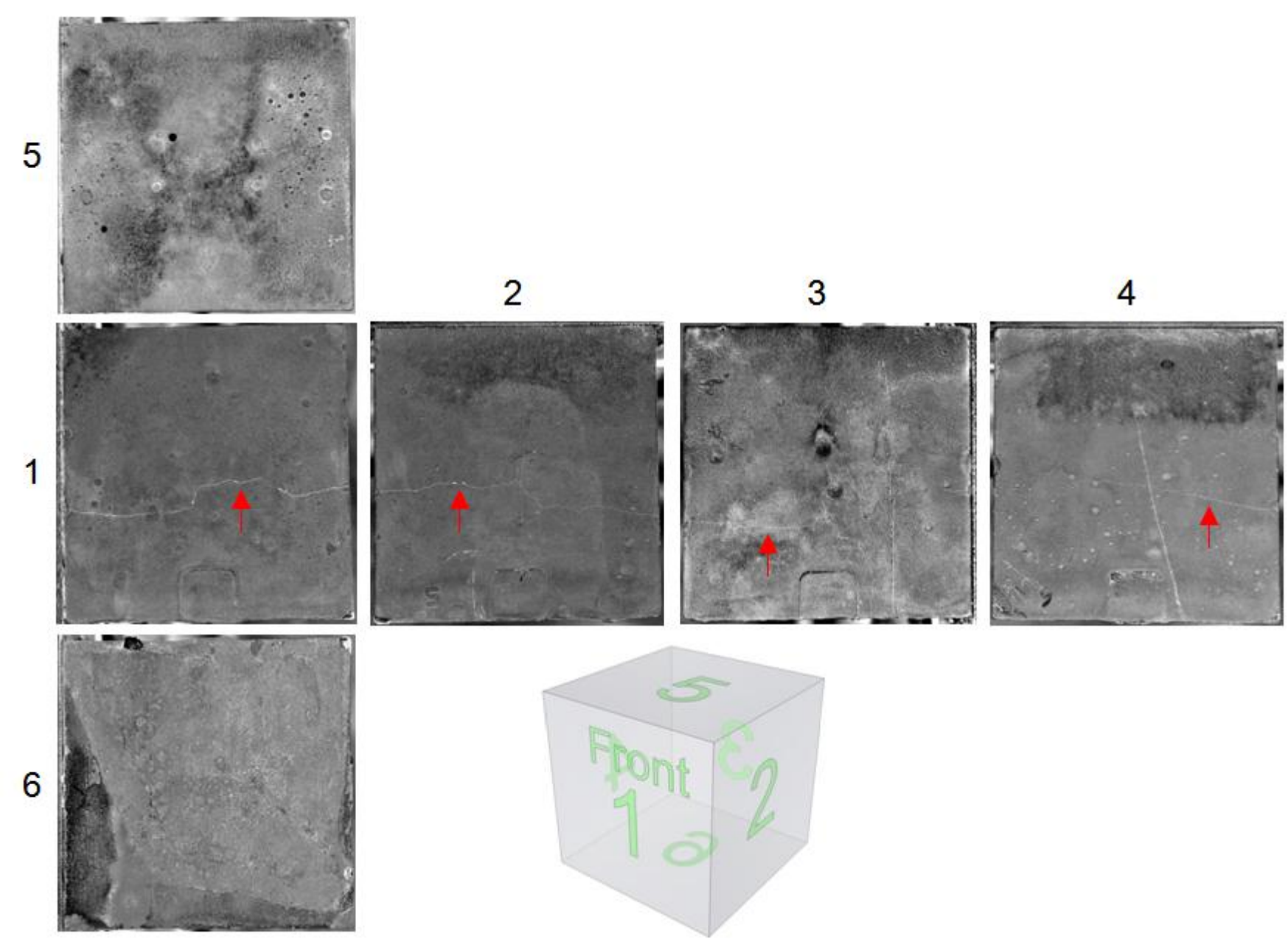

Fig. 5 Subtracted before and after images of block sides in semi-submersion test. Face numbers are labeled. Note the light colored fracture along the midline of faces $1,2,3$, and 4 . 


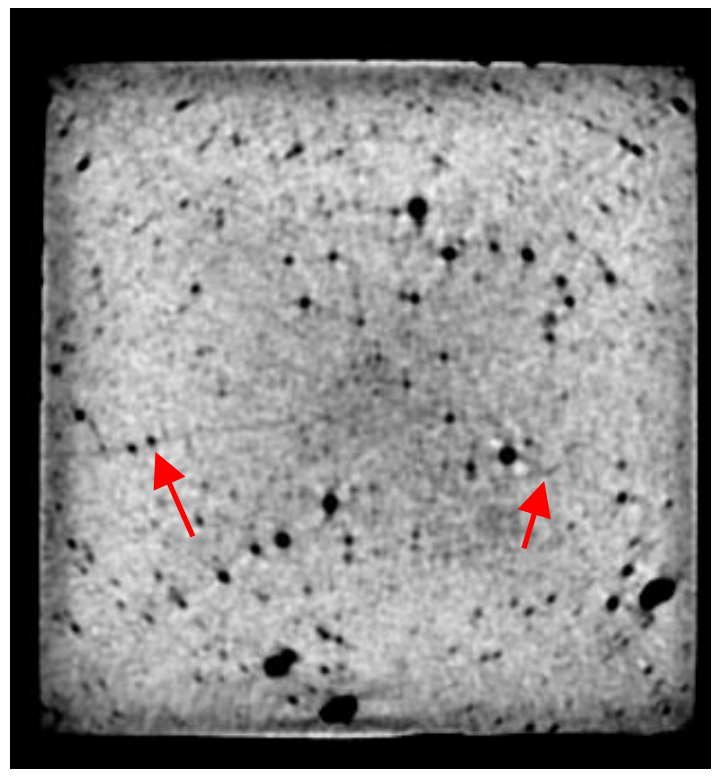

Fig. 6 CT scan showing a vertical slice through the middle of the block from the semisubmersion test. Arrows point to (darker) fractures in the block resulting from cryogenic fracturing. 


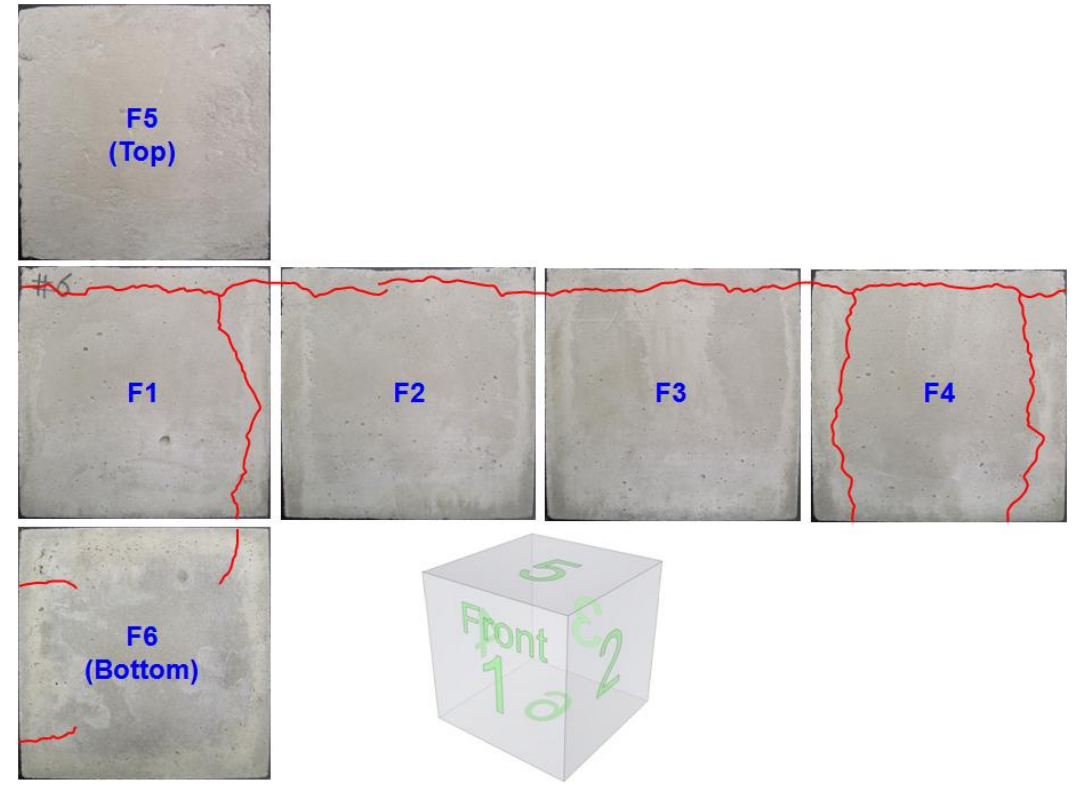

Fig. 7 Specimen after thermal shock - red lines are superimposed along the cracks to improve visibility. 


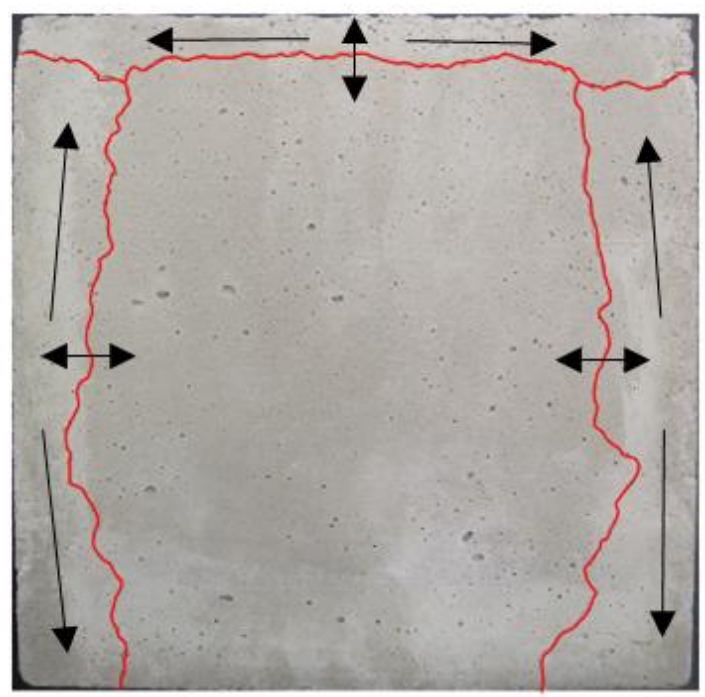

Fig. 8 Cracks created by the expansion of ice matrix (Face 4). 


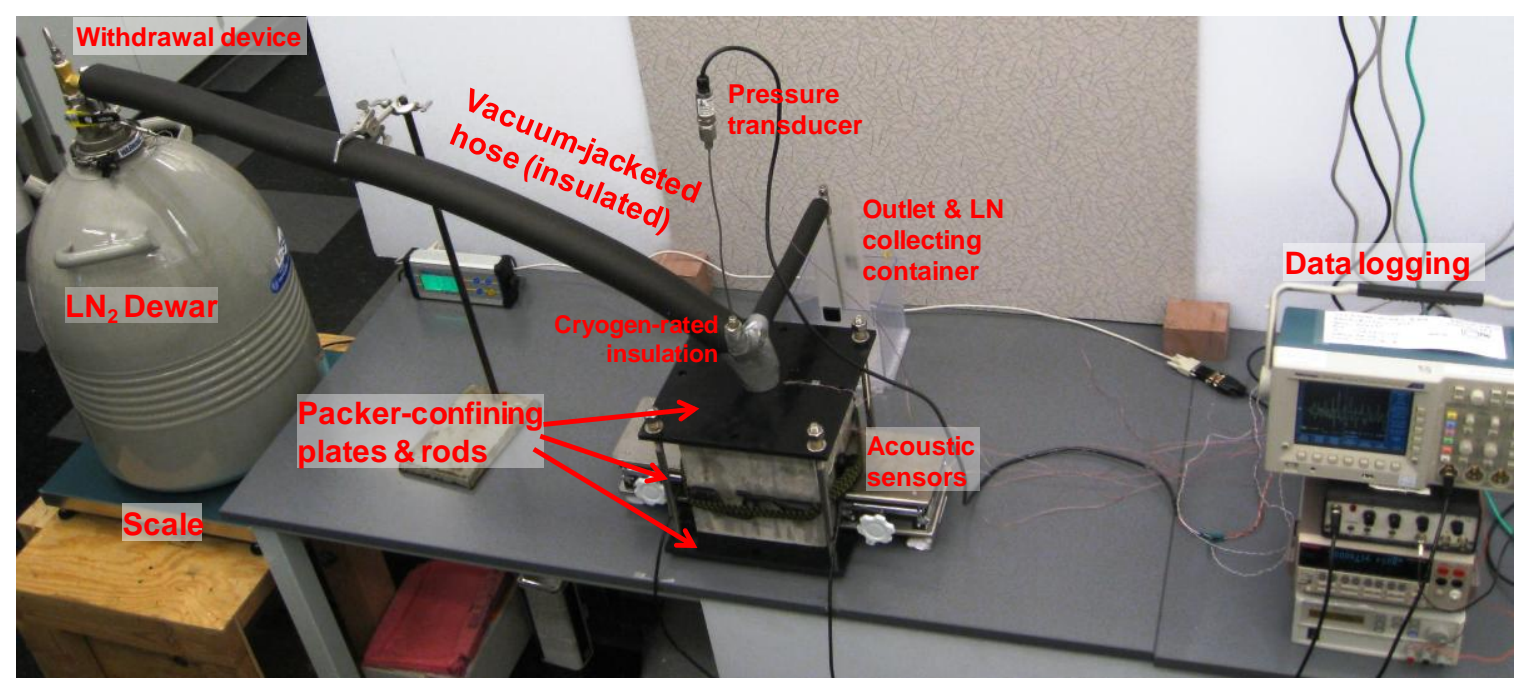

Fig. 9 Experimental setup with a "packer-confining structure" 


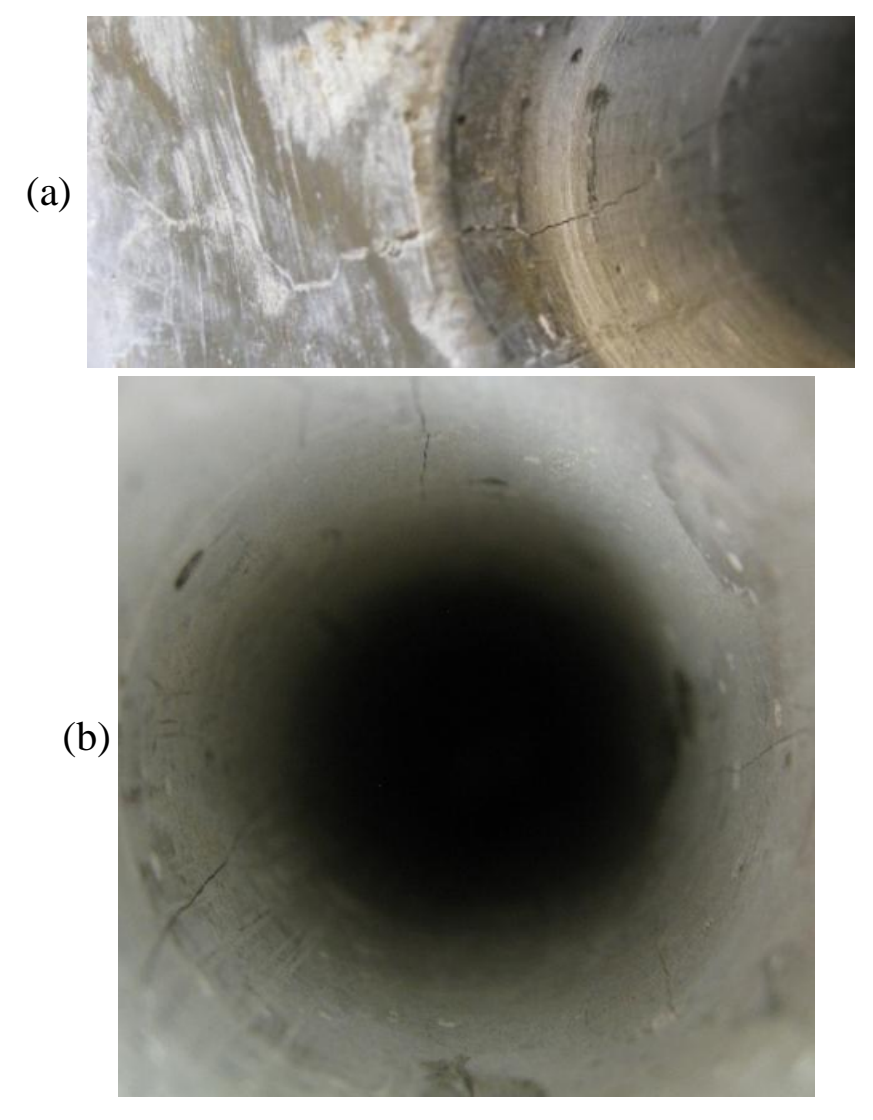

Fig. 10 Cracks observed after the thermal shocks. (a) near the borehole and (b) at the borehole surface - image from camera taken from the top. 


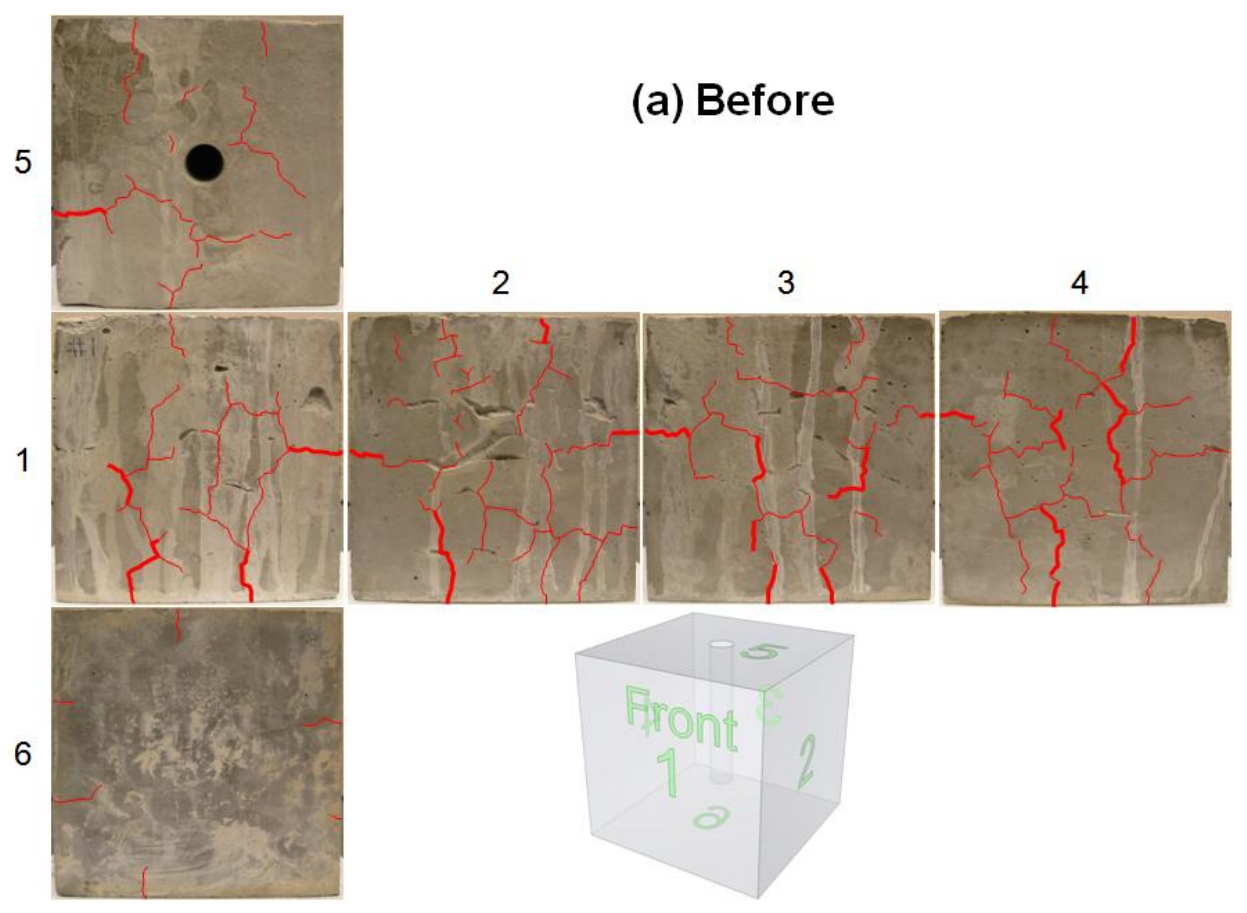

(b) After the $1^{\text {st }}$ thermal shock

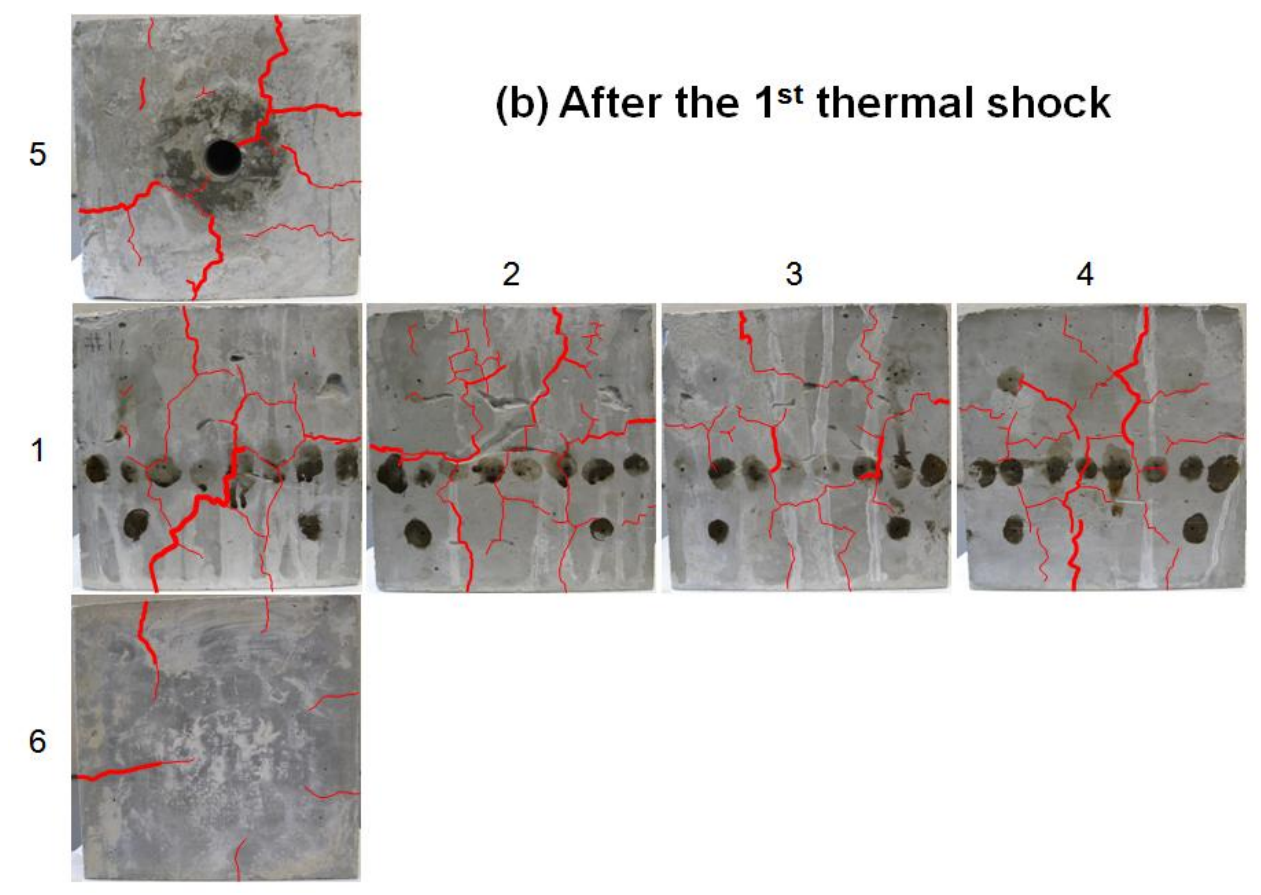




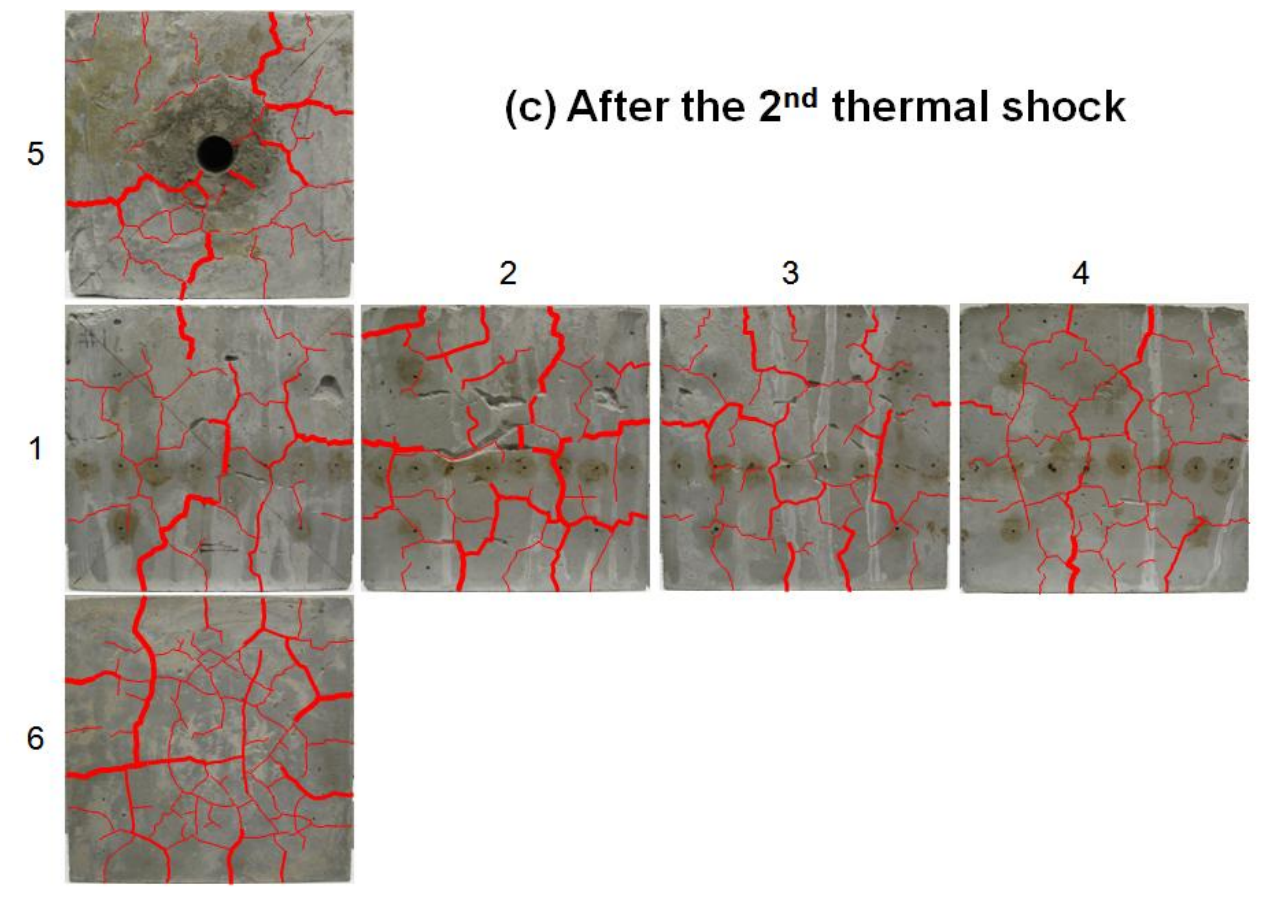

Fig. 11 Surface cracks. (a) Pre-existing surface cracks (b) Surface cracks after the $1^{\text {st }}$ thermal shock (c) after the $2^{\text {nd }}$ thermal shock - the superimposed lines are weighted according to the crack thickness. Note that the darker spots at Fig. 11b are stains from the coupling material used to attach the ultrasonic sensors. 


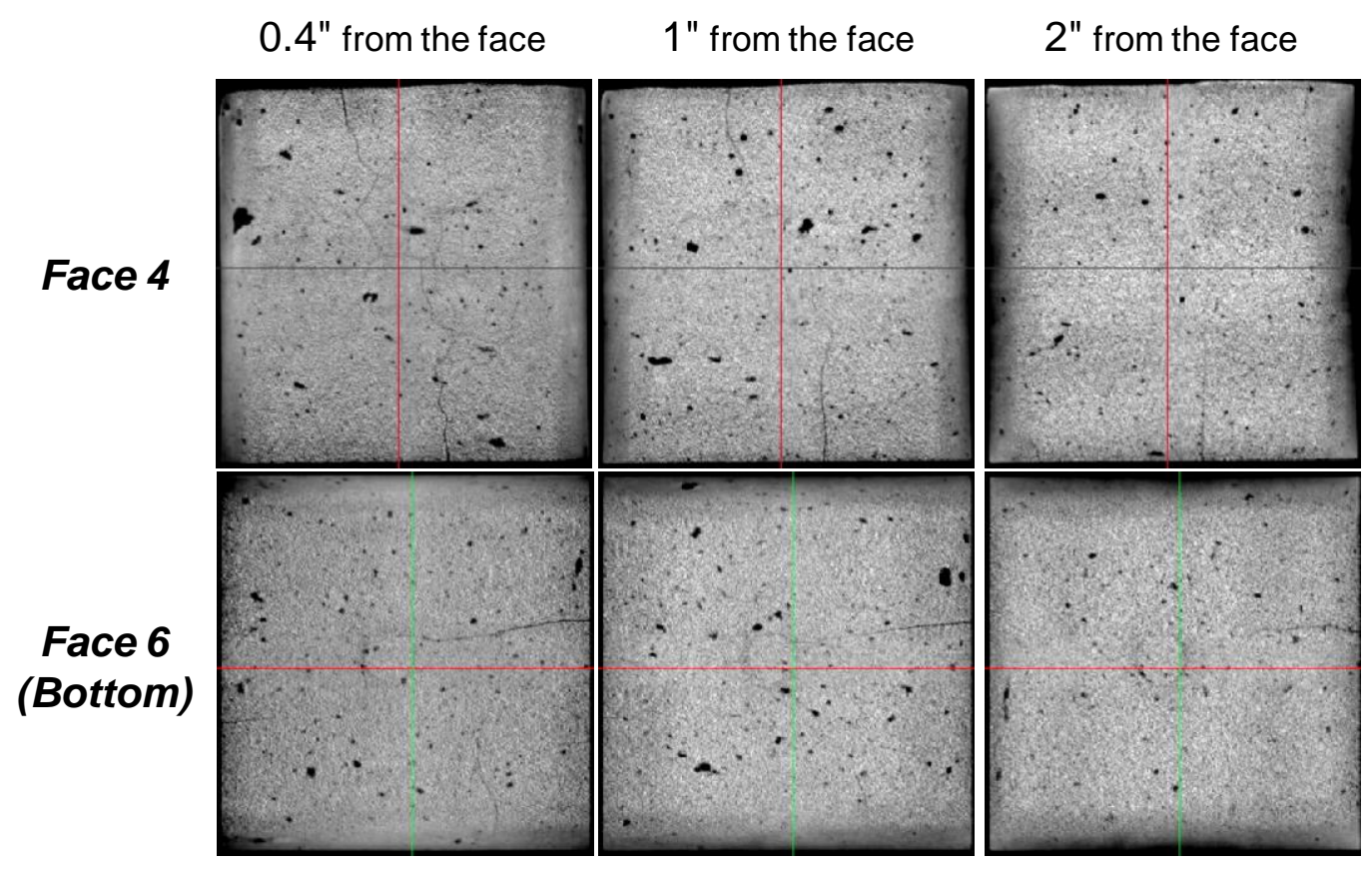

Fig. 12 The CT slices at 0.4", 1", and 2" away from Face 4 (vertical side) and Face 6 (Bottom). Cracks appear as darker features on the images. 

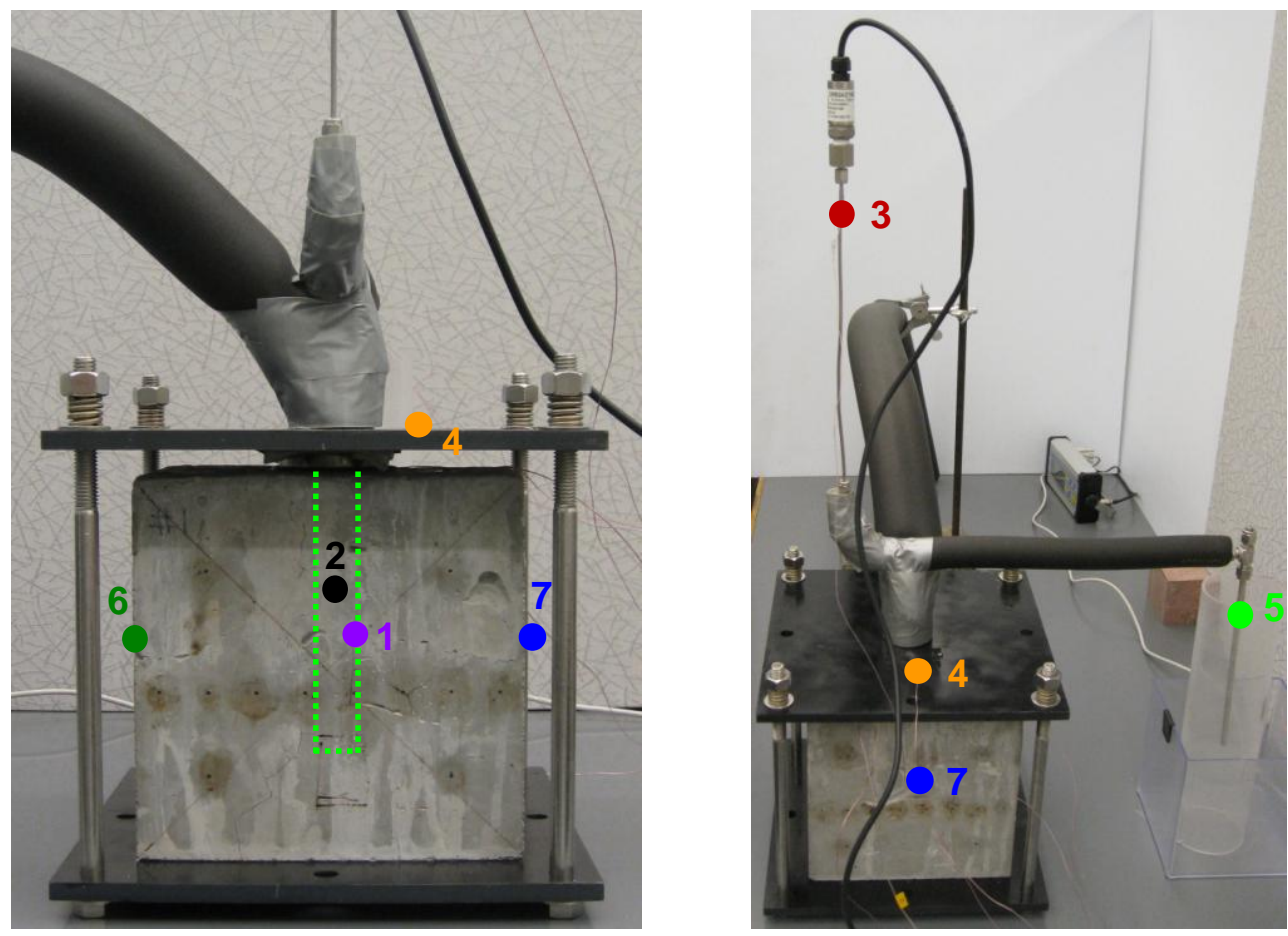

Fig. 13 Locations of the temperature sensors. 


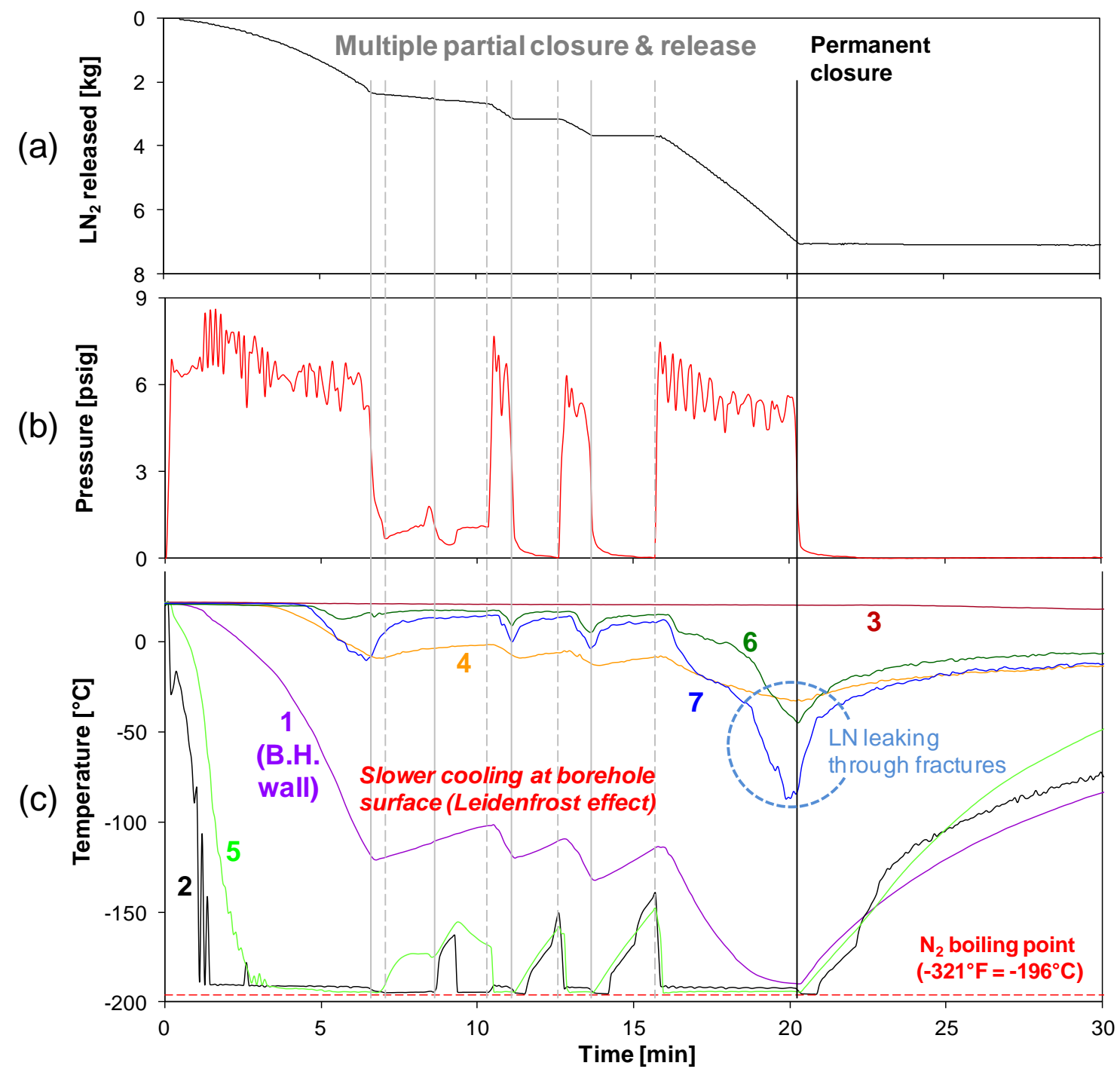

Fig. 14 Synchronized plots of $\mathrm{LN}_{2}$ consumption, pressure, and temperature with time (the $2^{\text {nd }}$ thermal shock). 

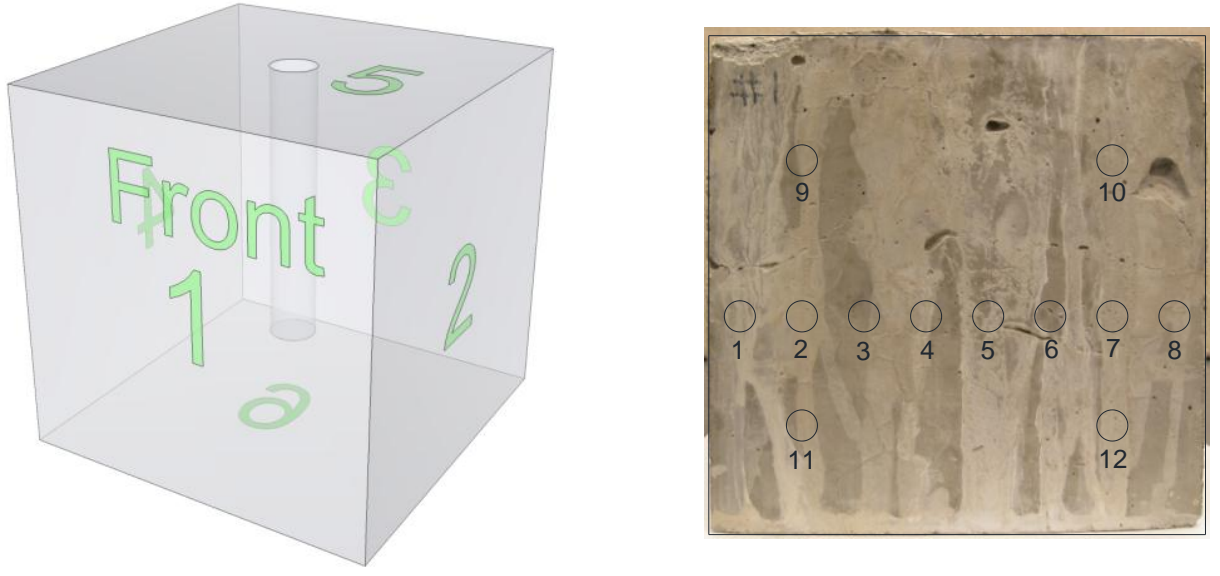

Fig. 15 Locations of acoustic measurement before and after thermal shock 
(a)

Before, after the $3^{\text {rd }}$, and after $4^{\text {th }}$ : delay in arrivals

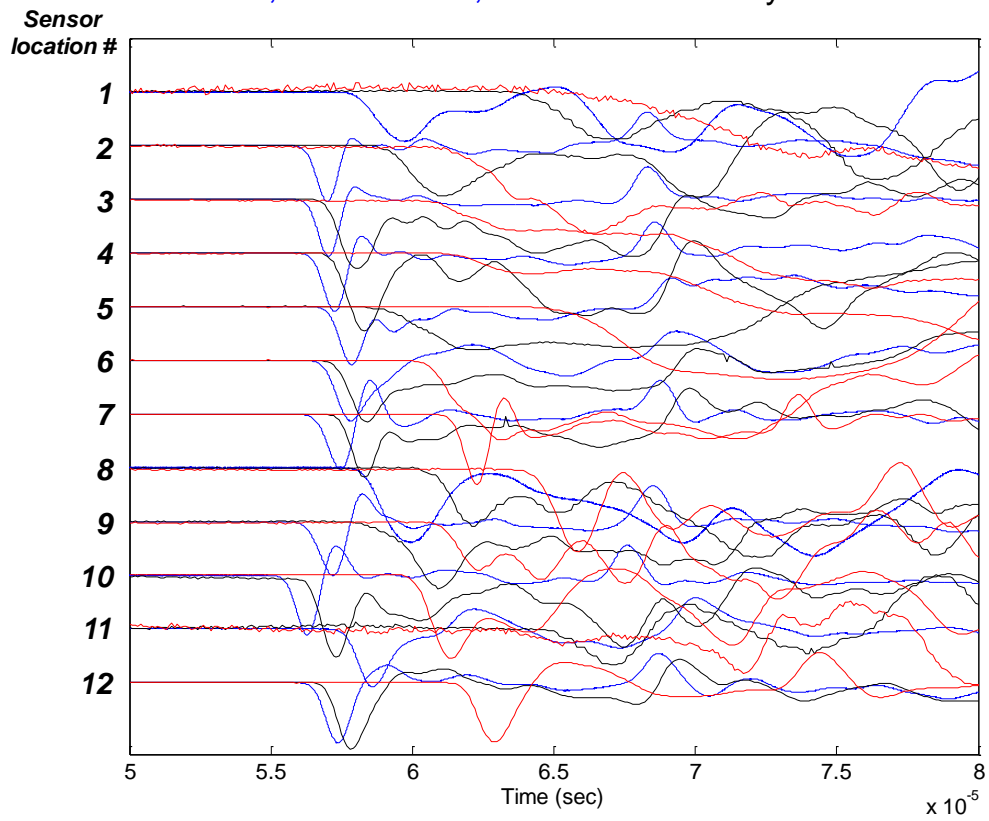

(b)

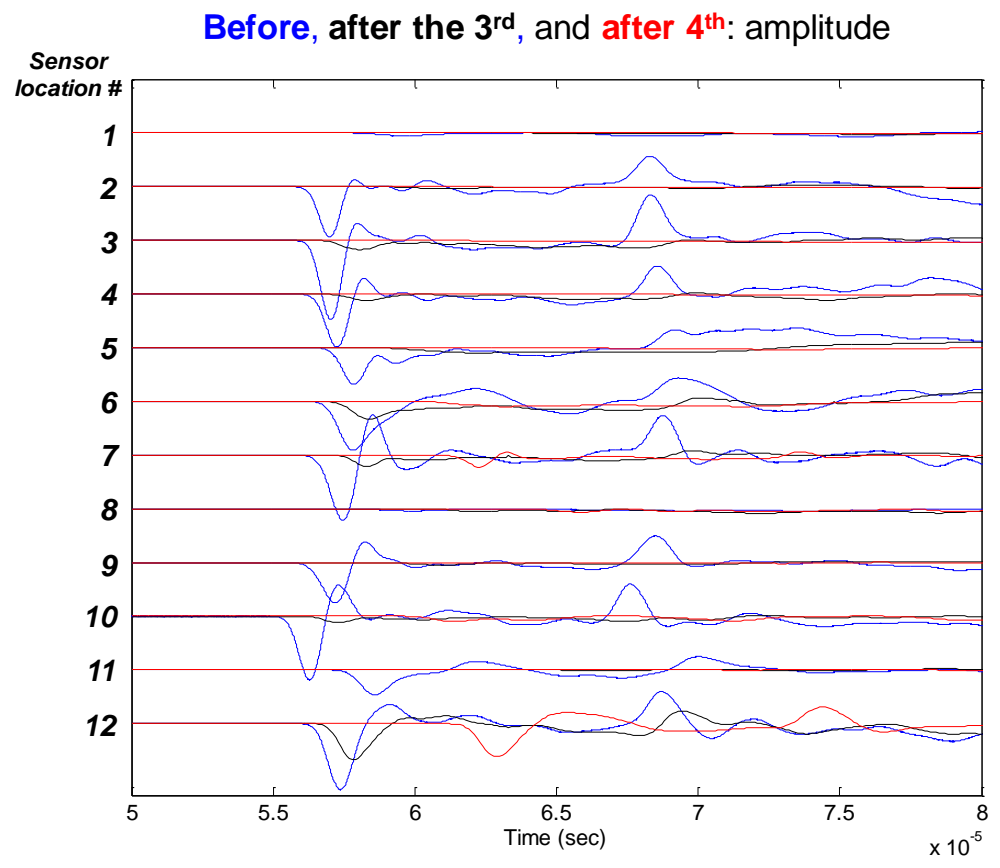

Fig. 16 P-wave signals near arrivals between Faces 1 and 3 before and after the thermal shock. (a) velocity changes - Normalized amplitude. (b) Amplitude changes - compared with original amplitude. 

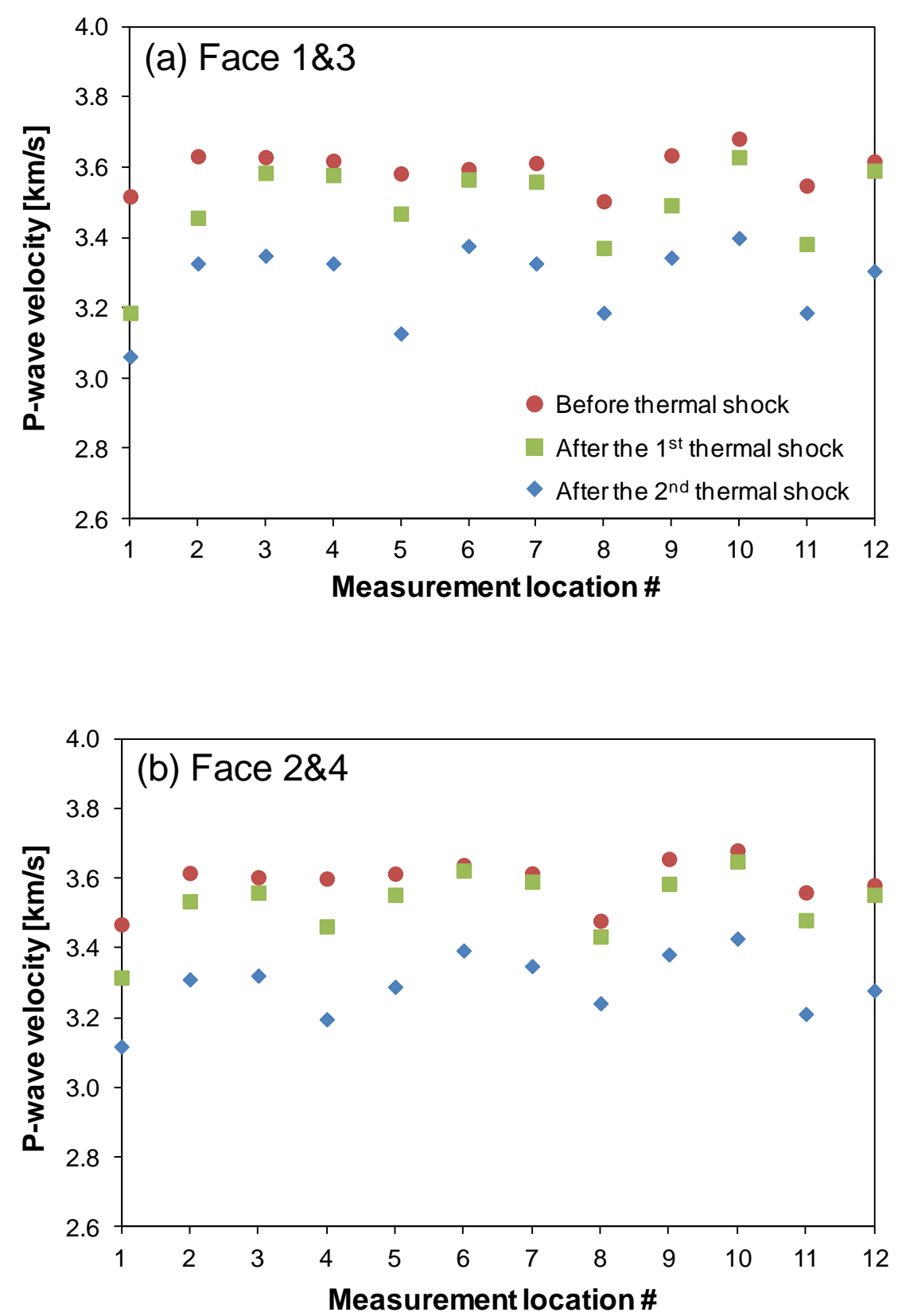

Fig. 17 Changes in P-wave velocities before and after the thermal shocks. 


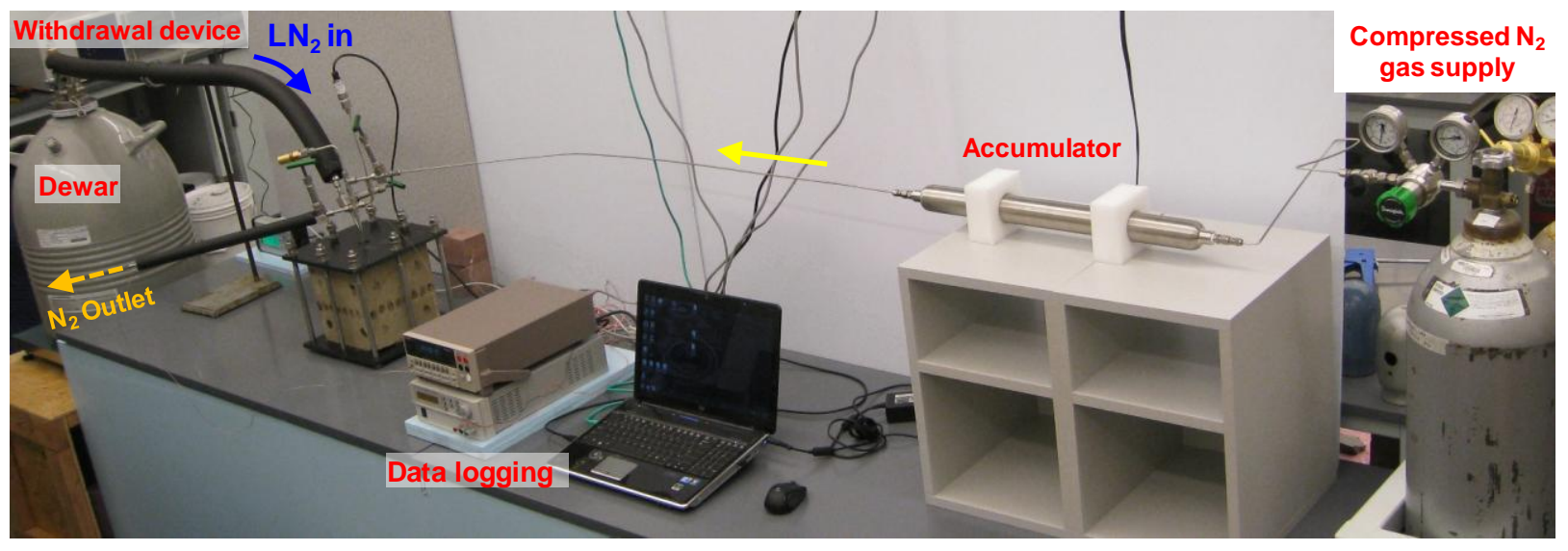

Fig. 18 Experimental setup for thermal shock and borehole pressurization (protection shields not shown). 


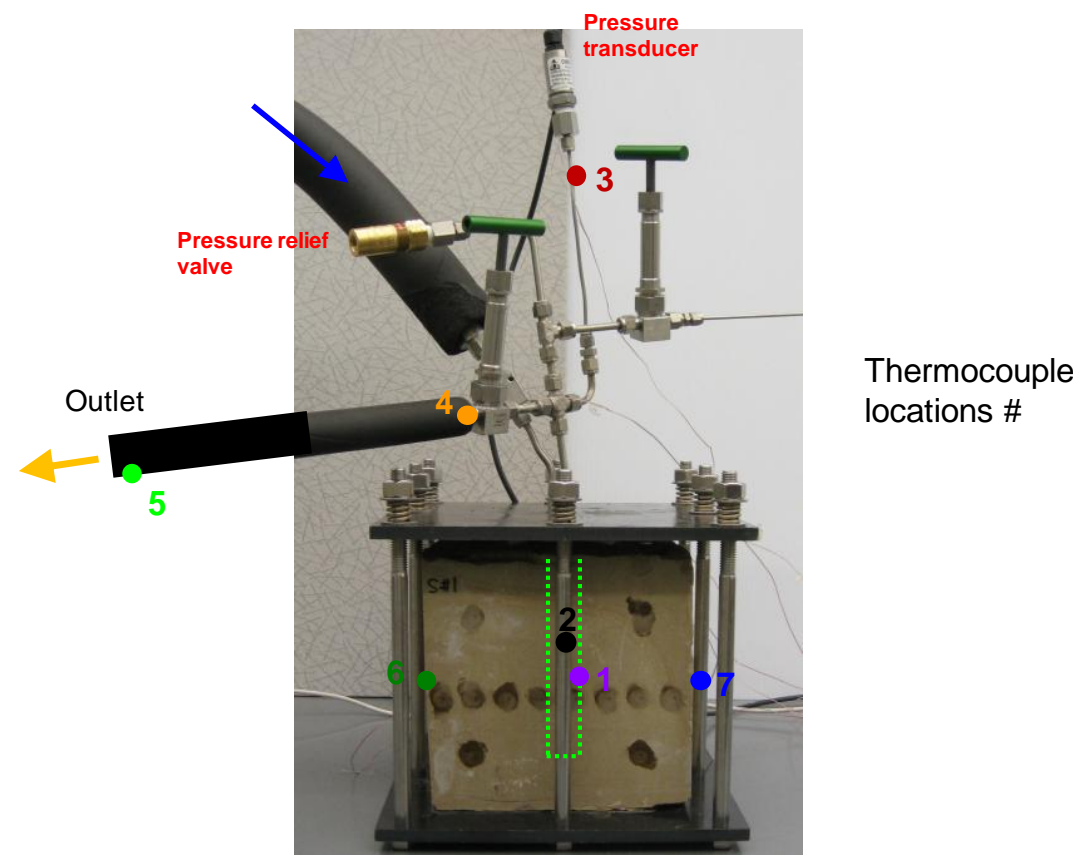

Fig. 19 Experimental setup near the specimen and locations of thermocouple tips (the picture were taken before insulation was applied). 
(a) Self-pressurization by $\mathrm{LN}_{2}$ vaporization

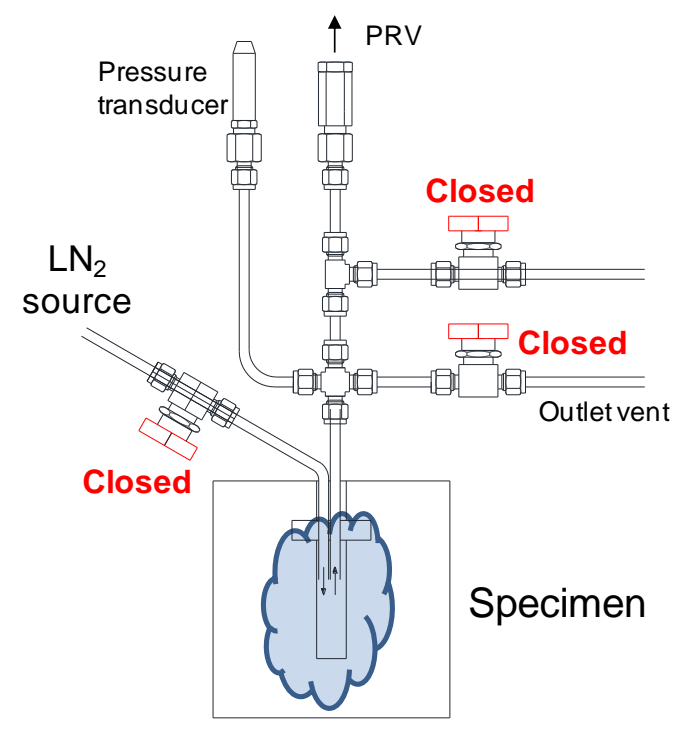

(b) Forced pressurization using compressed $\mathrm{N}_{2}$ gas

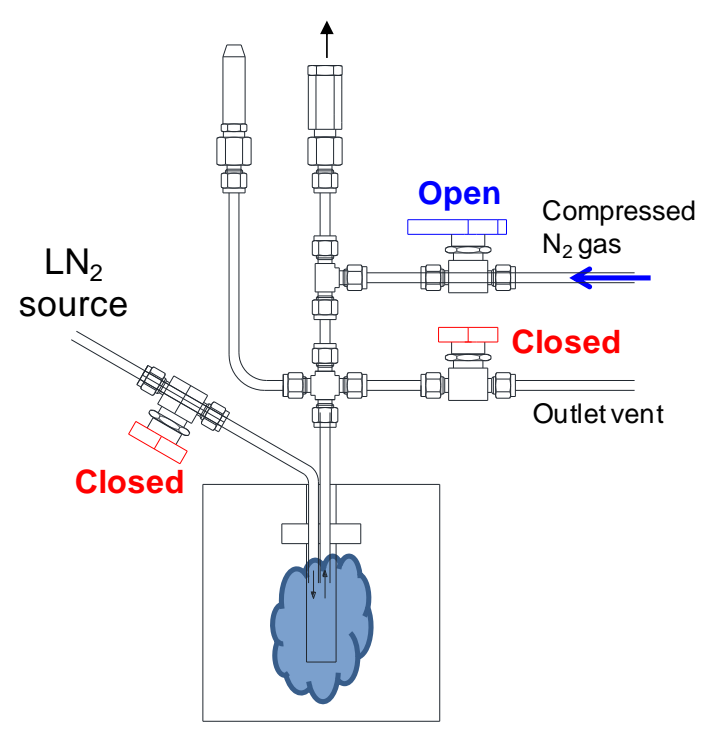

Fig. 20 Borehole pressurization schemes. 


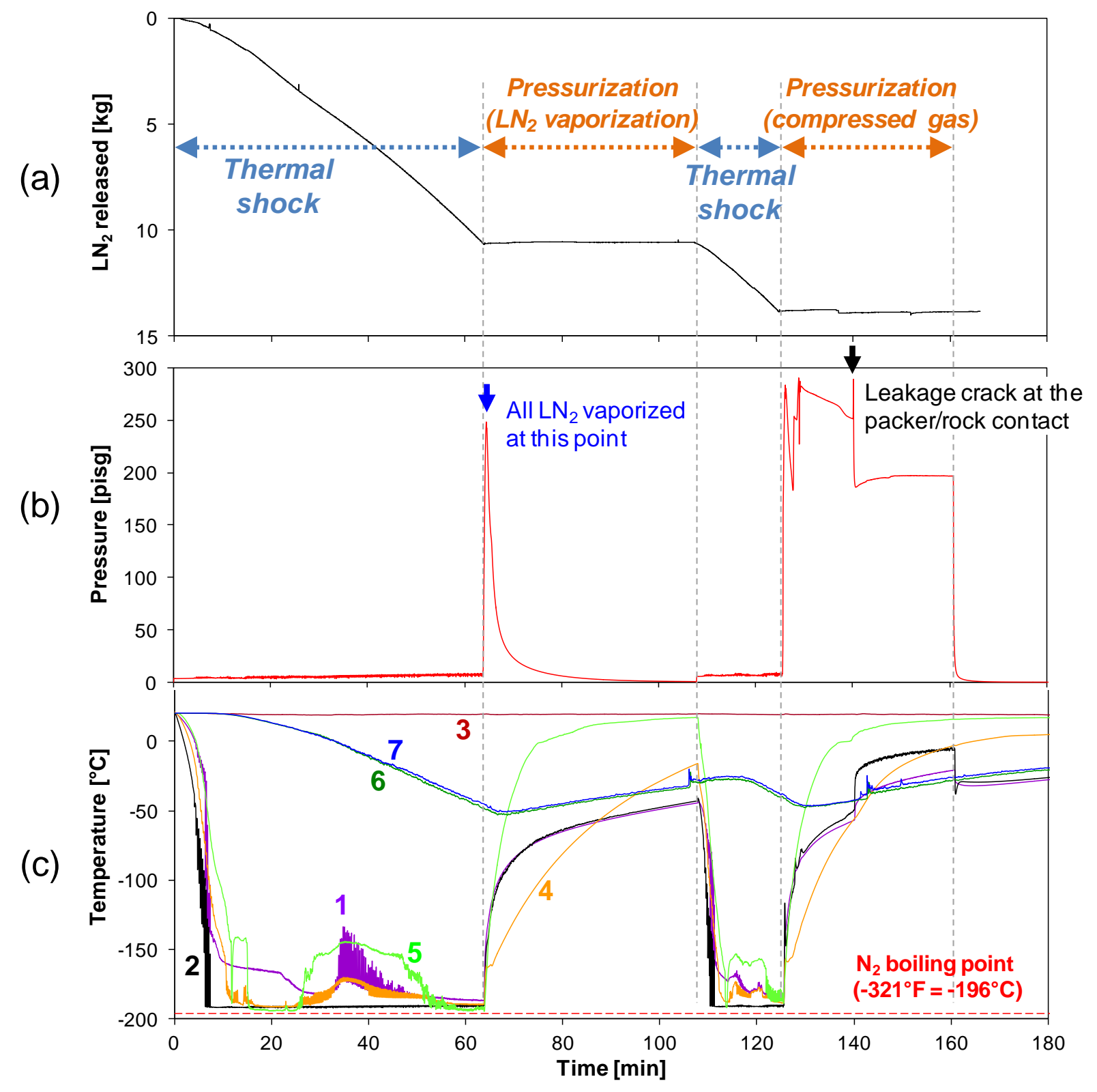

Fig. $21 \mathrm{LN}_{2}$ consumption, borehole pressure, temperature vs. time during the stimulation 
(a)

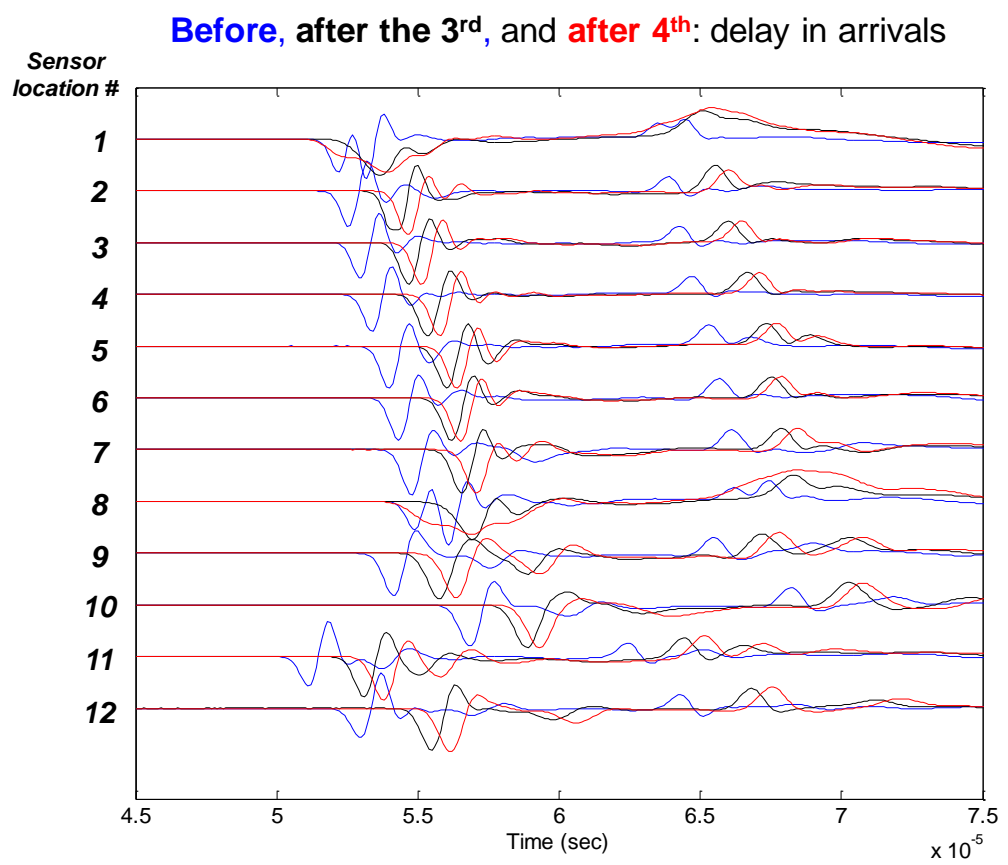

(c)

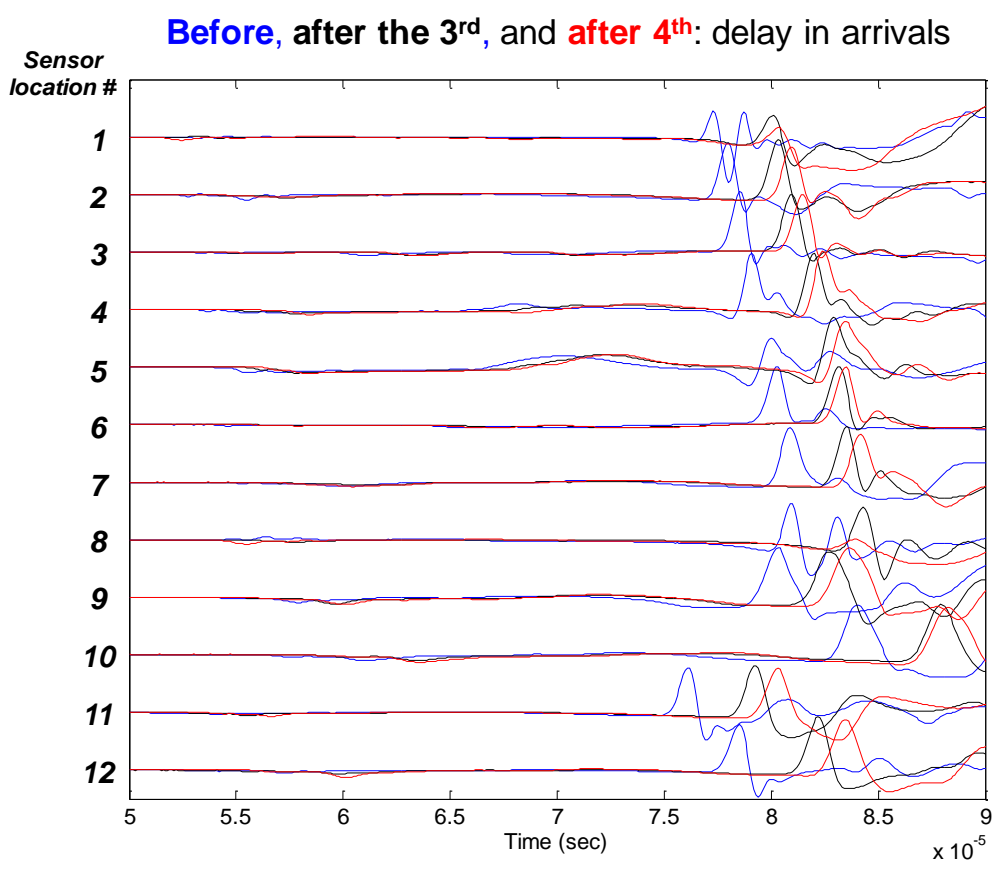

Fig. 22 Wave arrivals across Faces 1 and 3 before and after the cryogenic stimulation - compared with normalized amplitude. (a) P-waves. (b) S-waves. 

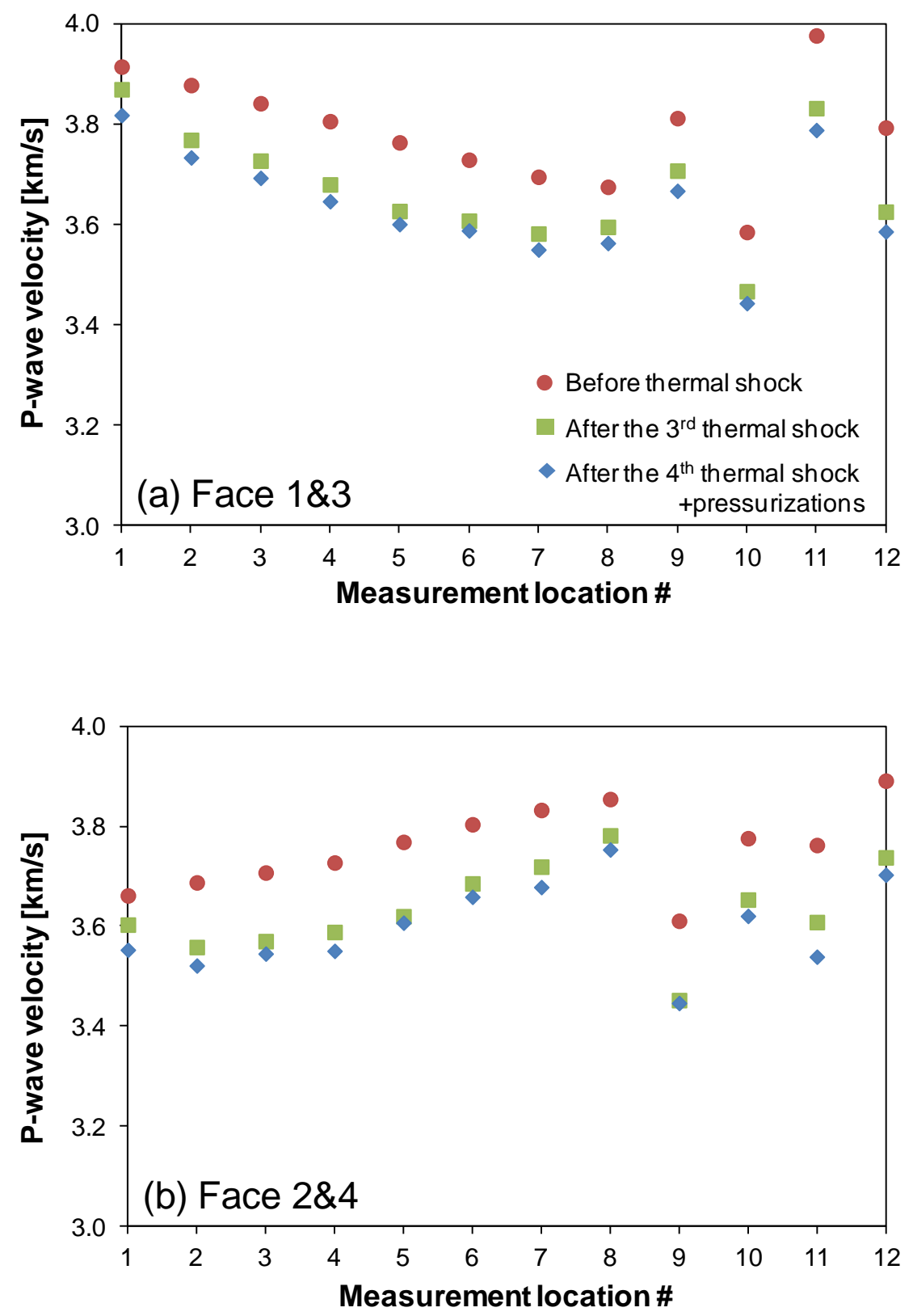

Fig. 23 P-wave velocity comparison (a) Measurement across Faces 1 and 3 (b) Measurement across Faces 2 and 4. 

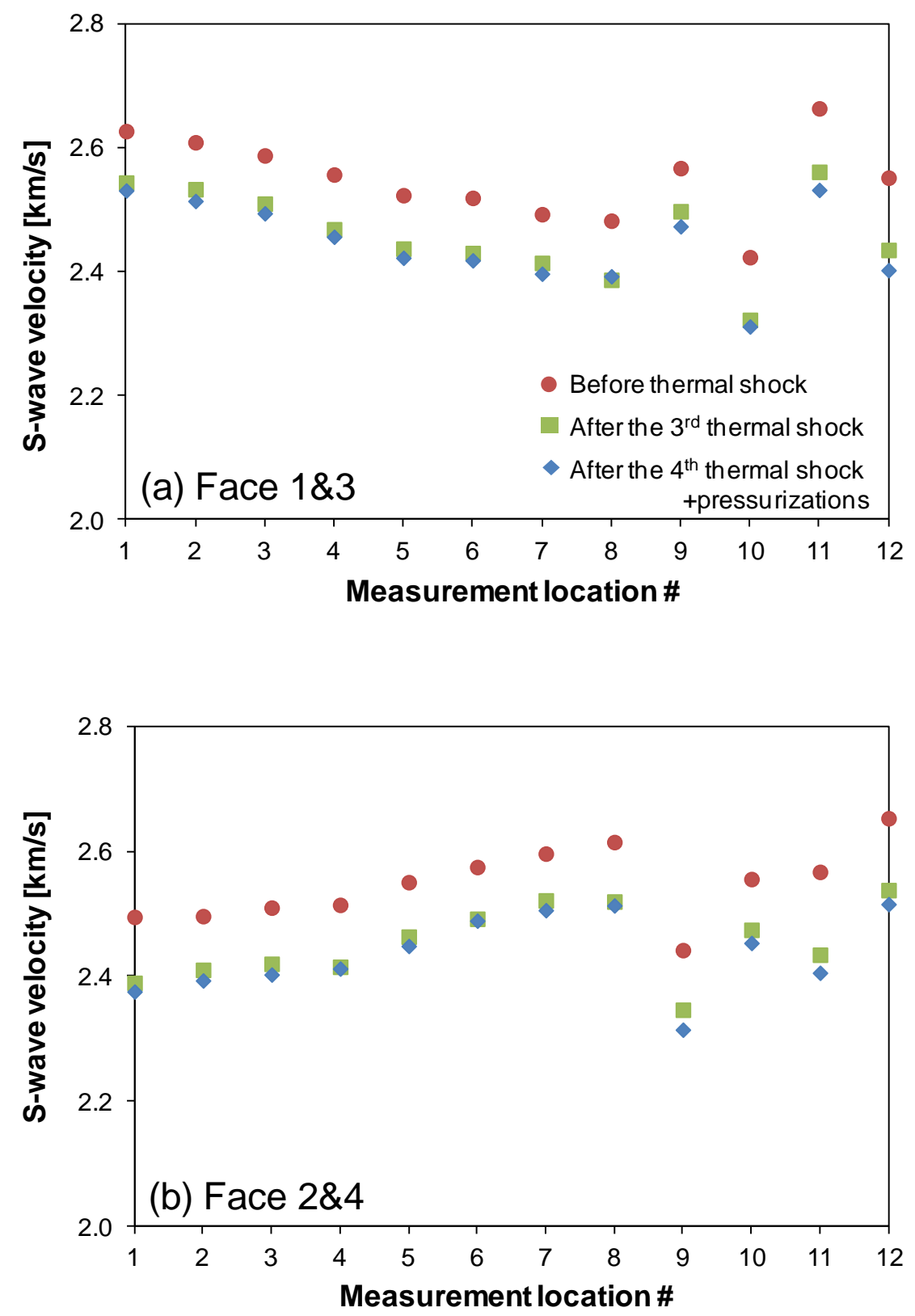

Fig. 24 S-wave velocity comparison (a) Measurement arcoss Faces 1 and 3 (b) Measurement across Faces 2 and 4. 
(a)

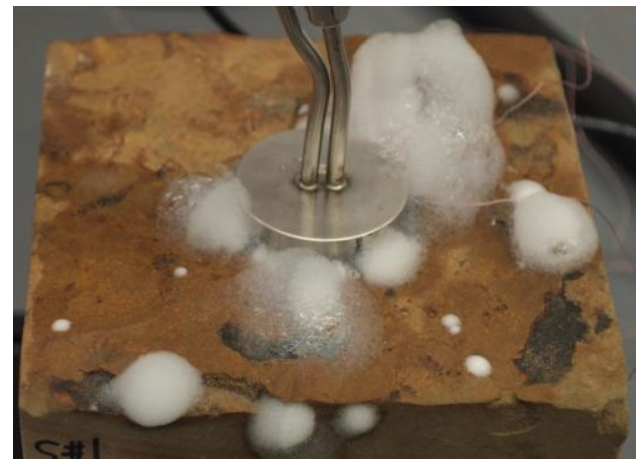

(b)

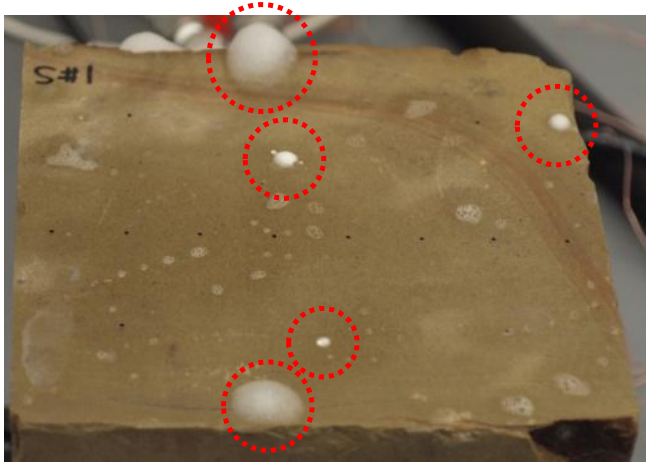

Fig. 25 Leakage/permeation test by bubbles. (a) Localized air permeation observed at the top. (b) Local permeation at the side (Face 1). 
(a)

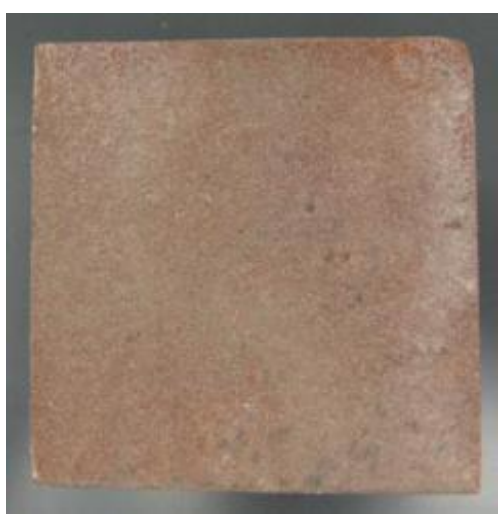

(b)

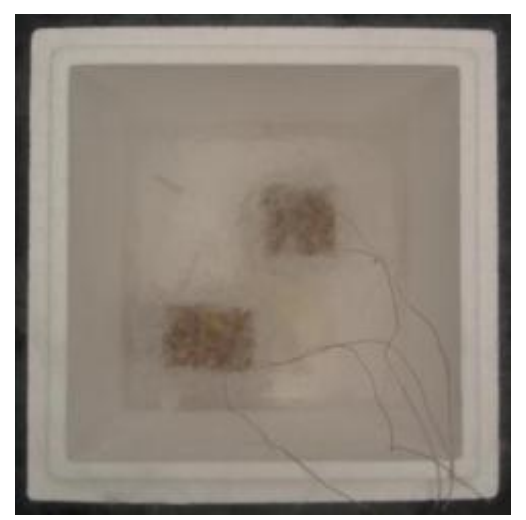

Fig. 26 Lyons Sandstone block under $\mathrm{LN}_{2}$. 


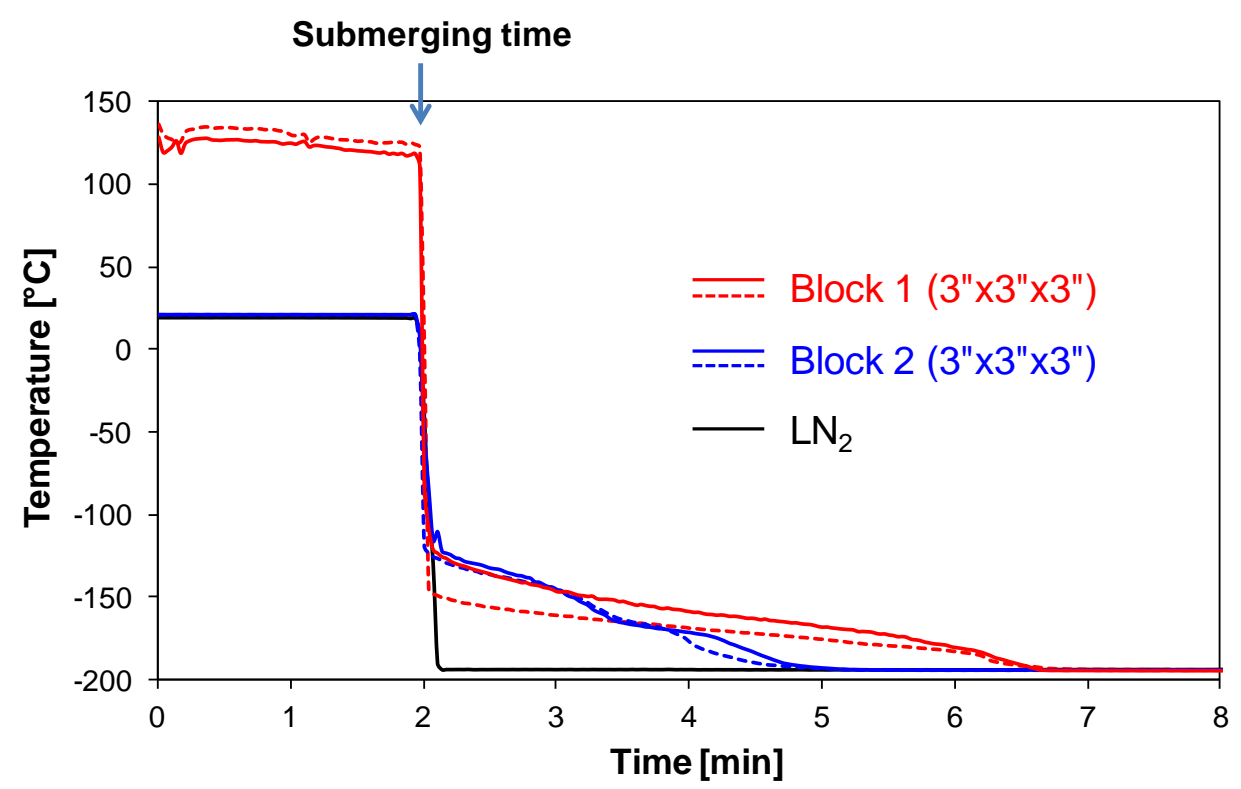

Fig. 27 Rock submersion test with temperature measurements. 